\title{
Non-Contacting Finger Seals Static Performance Test Results at Ambient and High Temperatures
}

\author{
Margaret P. Proctor ${ }^{1}$ \\ NASA Glenn Research Center, Cleveland, Ohio, 44135, USA
}

\begin{abstract}
The non-contacting finger seal is an advanced seal concept with potential to reduce specific fuel consumption in gas turbine engines by 2 to 3 percent with little to no wear of the seal or rotor. Static performance tests and bind-up tests of eight different non-contacting finger seal configurations were conducted in air at pressure differentials up to $689.4 \mathrm{kPa}$ and temperatures up to $922 \mathrm{~K}$. Four of the seals tested were designed to have lift pads concentric to a herringbone-grooved rotor which generates hydrodynamic lift when rotating. The remaining seals were tested with a smooth rotor; one seal had a circumferential taper and one had an axial taper on the lift pad inner diameter to create hydrodynamic lift during rotation. The effects of the aft finger axial thickness and of the forward finger inner diameter on leakage performance were investigated as well and compared to analytical predictions.
\end{abstract}

\begin{tabular}{|c|c|}
\hline$A$ & $=$ seal leakage area, $\mathrm{m}^{2}$ \\
\hline $\mathrm{C}$ & $=$ radial clearance, $\mathrm{mm}$ \\
\hline$D_{\text {seal }}$ & $=$ outside diameter of the seal rotor, $\mathrm{m}$ \\
\hline$\dot{m}$ & $=$ air leakage flow rate, $\mathrm{kg} / \mathrm{s}$ \\
\hline$P_{u}$ & $=$ air pressure upstream of seal, $\mathrm{MPa}$ \\
\hline$T_{a v g}$ & $=$ average seal air inlet temperature, $\mathrm{K}$ \\
\hline$T_{u}$ & $=$ upstream air temperature, $\mathrm{K}$ \\
\hline$\Delta \mathrm{P}$ & $=$ pressure drop across seal, $\mathrm{kPa}$ \\
\hline$\Phi$ & $=$ flow factor, kg-K $\mathrm{K}^{0.5} / \mathrm{MPa}-\mathrm{m}-\mathrm{s}$ \\
\hline$\phi_{\text {leveled }}$ & $=$ leveled flow factor, kg-K $\mathrm{K}^{0.5} / \mathrm{MPa}-\mathrm{m}-\mathrm{s}$ \\
\hline$\phi_{\max }$ & $=$ maximum flow factor, kg-K $\mathrm{K}^{0.5} / \mathrm{MPa}-\mathrm{m}-\mathrm{s}$ \\
\hline
\end{tabular}

\section{Introduction}

$\mathrm{O}$

VER the years, gas turbine engine system studies have shown that use of advanced low leakage seals has potential to reduce specific fuel consumption by 2-3 percent and reduce direct operating costs. ${ }^{1}$ Brush seals and finger seals have leakage rates that are less than half of the leakage rate of conventional labyrinth seals. However, both brush and finger seals are contacting seals and wear over time. ${ }^{2,3}$ As gas turbine engines advance, the operating conditions for dynamic seals become more severe and sealing requirements more challenging. Contacting seals are not practical because the rubbing contact generates heat that affects not only the seal, but downstream components that are already near the limit of their temperature capability. In view of this, research efforts have been directed towards developing compliant, non-contacting seal designs. One of several compliant, non-contacting seal designs is the non-contacting finger seal (NCFS).

Development of the non-contacting finger seal can be traced back to 1998, when AlliedSignal patented the noncontacting finger seal with hydrodynamic foot portion ${ }^{4}$ that has lift pads extending axially upstream and downstream from the forward and aft finger elements, respectively. In 2004, NASA patented a non-contacting finger seal ${ }^{5}$ that has lift pads only extending axially downstream from the downstream fingers. With NASA support, the University of Akron did some analysis and ambient rig testing of the non-contacting finger seal ${ }^{6-8}$ and subsequently patented a noncontacting finger seal with lift pads extending from both forward and aft fingers in the downstream direction only. ${ }^{9}$

Preliminary testing of the NASA baseline non-contacting finger seal on a herringbone-groove rotor at $300 \mathrm{~K}$ and $5000 \mathrm{rpm}$ demonstrated non-contacting operation at pressures from 14 to $241 \mathrm{kPa}$ and no measurable wear after

\footnotetext{
${ }^{1}$ Research Mechanical Engineer, Mechanisms and Tribology Branch, 21000 Brookpark Road, and non-member.
} 
93 minutes of rotation. During static testing, it was found that excessive pressure differential caused the seal to bind the shaft. ${ }^{10}$ Subsequent study was undertaken to investigate how certain geometry changes affect the leakage performance and the pressure differential capability of the non-contacting finger seal. This paper presents the static performance test results of the NASA non-contacting finger seal designs at 294, 533, 700, and $922 \mathrm{~K}$ inlet air temperature for eight different versions, or builds, of the seal. After the test hardware, apparatus, and procedures are described, the leakage performance test results are presented and discussed, and compared to predictions. The test results and discussion of the bind-up pressure, hardware inspections, and conclusions follow.

\section{Test Hardware}

\section{A. Non-Contacting Finger Seal Baseline Design}

The non-contacting finger seal baseline design, Figure 1, is comprised of forward (upstream) and aft (downstream) finger elements sandwiched between forward and aft spacers and front and back cover plates. The assembly is held together with 20 screws. Typical finger seals would be fastened together with rivets ground flush with the front and back plates. Also, the back plate would typically be about the same thickness as the front plate. This seal was designed with a much thicker back plate to accommodate fastening components with screws so that different finger elements could be tested without replacing all the individual seal components.

The finger elements are thin washers with a series of curved slots all around the inner diameter, which form the fingers. The two finger elements are oriented so that the fingers of one element cover the gaps between the fingers of the other element. The fingers act as cantilever beams, flexing in response to rotor dynamic motion and radial growth of the rotor due to centrifugal and thermal forces. This compliant feature permits operation at clearances much smaller than fixed clearance seals, resulting in lower leakage rates.

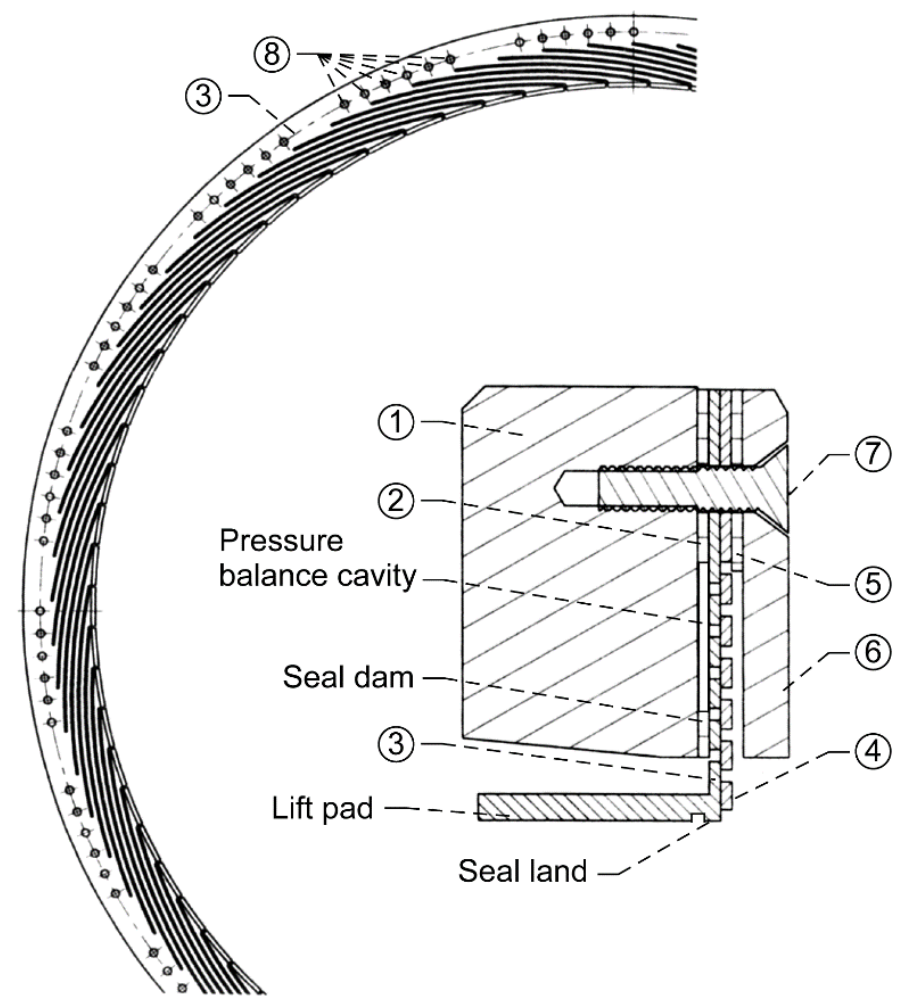

Figure 1. Noncontacting finger seal design: 1, back plate; 2, aft spacer; 3 , aft finger element; 4, forward finger element; 5 , forward spacer; 6 , front plate; 7 , screw; 8 , indexing and screw holes. 
The aft finger element has lift pads that extend axially downstream from each finger at the seal inner diameter and that are concentric to the rotor at build. The lift pads ride above herringbone grooves on the outer diameter of the rotor. Each lift pad has a circumferential groove on the inner diameter, Figure 2. This groove defines the end of the seal land just upstream of it. The circumferential grooves, which create a flow path to the low pressure region between the lift pads downstream of the aft finger stick, are assumed to be at low pressure. Thus, the portion of the lift pad downstream of the circumferential groove has low pressure on all four sides. The seal is positioned so that the upstream edge of the herringbone groove is located at the middle of the circumferential groove on the lift pad inner diameter.

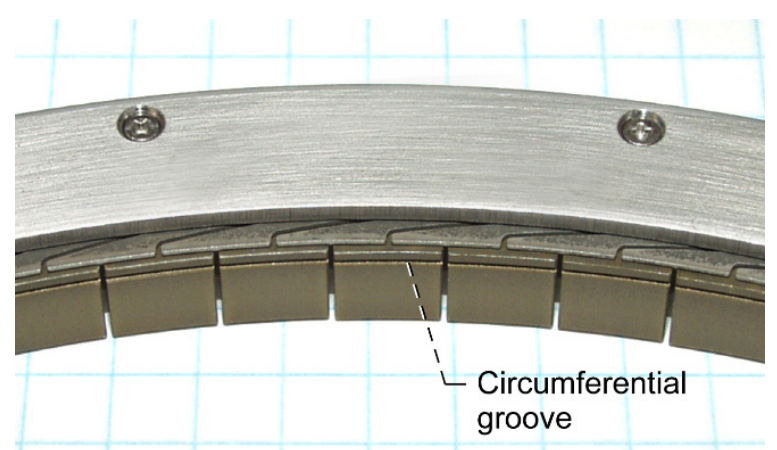

Figure 2. Pre-test photo of non-contacting finger seal inner diameter. During rotation, the grooves pump air inward towards the center of the lift pads to create a hydrodynamic lifting force to prevent contact with the rotor.

Another difference between the forward and aft finger elements is that the high pressure finger element has an inner diameter that is $0.762 \mathrm{~mm}$ larger than the low pressure finger element. This was done to ensure that the high pressure finger element, which has no lift pads, would not touch the rotor due to pressure blow down effects. Applying a pressure differential across a finger seal generates a suction force that draws the fingers inwards towards the rotor due to the lower pressure under the finger pads. It may be possible to reduce the high pressure finger element inner diameter to match the low pressure finger element if there is sufficient friction between the two elements to keep them moving together. Evidence that this is the case can be found in Refs. 6, 7, and 8.

The forward spacer extends radially inward from the outer diameter of the seal to the root of the finger stick. The aft spacer forms the pressure balance cavity between the aft finger element, the back plate and seal dam. High pressure is fed to the balance cavity through a series of slots in the spacers and holes in the finger elements. The pressure balance cavity reduces the normal force, and hence the friction force, at the seal dam. This is essential to reducing hysteresis in the seal.

The non-contacting finger seals are made of Haynes-188, a solid-solution-strengthened super-alloy, for operations at temperatures up to $1089 \mathrm{~K}$. The baseline design, Build 1, dimensions are shown in Table 1, as well as the dimensions for the seven other builds.

Table 1. Key dimensions of non-contacting finger seals tested.

\begin{tabular}{|c|c|c|c|c|c|c|c|c|c|c|c|}
\hline \multirow{2}{*}{$\begin{array}{c}\text { Build } \\
\text { no. }\end{array}$} & \multirow[t]{2}{*}{ Description } & \multicolumn{3}{|c|}{ Aft finger element } & \multirow{2}{*}{$\begin{array}{c}\text { Finger pad } \\
\text { Circum. } \\
\text { length } \\
\text { at ID } \\
(\mathrm{mm}) \\
\end{array}$} & \multicolumn{2}{|c|}{ Forward finger element } & \multicolumn{2}{|c|}{ Rotor } & \multicolumn{2}{|c|}{ Radial clearance } \\
\hline & & $\begin{array}{l}\text { Inner } \\
\text { diam. } \\
(\mathrm{mm})\end{array}$ & $\begin{array}{l}\text { Axial } \\
\text { finger } \\
\text { thickness } \\
(\mathrm{mm})\end{array}$ & $\begin{array}{l}\text { Lift pad } \\
\text { axial length } \\
\text { at ID } \\
(\mathrm{mm})\end{array}$ & & $\begin{array}{l}\text { Inner } \\
\text { diam. } \\
(\mathrm{mm})\end{array}$ & $\begin{array}{c}\text { Axial } \\
\text { finger } \\
\text { thickness } \\
(\mathrm{mm})\end{array}$ & $\begin{array}{l}\text { Outer } \\
\text { diam. } \\
(\mathrm{mm})\end{array}$ & Finish & $\begin{array}{l}\text { Aft } \\
(\mathrm{mm})\end{array}$ & $\begin{array}{c}\text { Forward } \\
(\mathrm{mm})\end{array}$ \\
\hline 1 & Baseline & 215.93 & 0.419 & $8.08-8.10$ & 7.92 & $216.66-216.69$ & 0.419 & 215.88 & HB & 0.024 & 0.3962 \\
\hline 2 & Baseline with same ID & 215.93 & 0.419 & $8.08-8.10$ & 7.92 & 215.92 & 0.432 & 215.88 & $\mathrm{HB}$ & 0.024 & 0.0190 \\
\hline 3 & Baseline with $2 x$ aft finger & 215.92 & 0.775 & 8.23 & $7.98^{*}$ & $216.66-216.69$ & 0.419 & 215.88 & HB & 0.02 & 0.3962 \\
\hline 4 & $2 \mathrm{x}$ aft finger and same ID & 215.92 & 0.775 & 8.23 & $7.98^{*}$ & 215.92 & 0.432 & 215.88 & HB & 0.02 & 0.0190 \\
\hline $5 a$ & Build 1 on smooth rotor & 215.93 & 0.419 & $8.08-8.10$ & 7.92 & $216.66-216.69$ & 0.419 & 215.9 & Smooth & 0.015 & 0.3873 \\
\hline $5 b$ & Build 3 on smooth rotor & 215.92 & 0.775 & 8.23 & $7.98^{*}$ & $216.66-216.69$ & 0.419 & 215.9 & Smooth & 0.0089 & 0.3873 \\
\hline 6 & $0.0127 \mathrm{~mm}$ circum. taper & 215.91 & 0.394 & 8.23 & $7.98^{*}$ & 215.92 & 0.432 & 215.9 & Smooth & 0.0025 & 0.0102 \\
\hline \multirow[t]{3}{*}{7} & $0.0127 \mathrm{~mm}$ axial taper & & 0.394 & 8.23 & $7.98^{*}$ & 215.92 & 0.432 & 215.9 & Smooth & & 0.0102 \\
\hline & - upstream edge & 215.91 & & & & & & 215.9 & & 0.0025 & \\
\hline & - downstream edge & 215.88 & & & & & & 215.9 & & -0.0102 & \\
\hline
\end{tabular}

*(inspected ID $\times \mathrm{Pi}) / 81$ - 0.41 design gap between fingers

\begin{tabular}{lccc}
\hline \hline & \multicolumn{3}{c}{ Circumferential groove } \\
\cline { 2 - 4 } & $\begin{array}{c}\text { Depth } \\
(\mathrm{mm})\end{array}$ & $\begin{array}{c}\text { Axial length } \\
(\mathrm{mm})\end{array}$ & $\begin{array}{c}\text { Location from } \\
\text { upstream edge } \\
(\mathrm{mm})\end{array}$ \\
\hline Builds 1, 2, 5a & 0.318 & 0.79 & 0.84 \\
\hline Builds 3, 4, 5b & 0.356 & 0.76 & 1.14 \\
\hline \hline
\end{tabular}




\section{B. Builds 2 to 7}

The other builds were designed to test the effect of certain features. Specifically, Build 2 has a forward finger element that has nearly the same inner diameter as the aft finger element. Build 3 has double the axial finger thickness than the baseline seal. Build 4 combines the features of Builds 2 and 3. Build 5a is the baseline design, Build 1, on a smooth rotor. Build $5 \mathrm{~b}$ is Build 3 on a smooth rotor. Two of the NCFS designs were tested on a smooth rotor and relied on hydrodynamic features in the lift pads. Specifically, Build 6 has a lift pad with a 0.0127-mm circumferential taper that creates a clearance that converges in the direction of rotation and Build 7 has a lift pad with a 0.0127-mm axial taper that converges with the axial direction of flow. A graphical summary of Builds 1 to 7 , shown in Figure 3, illustrates the differences between the builds.

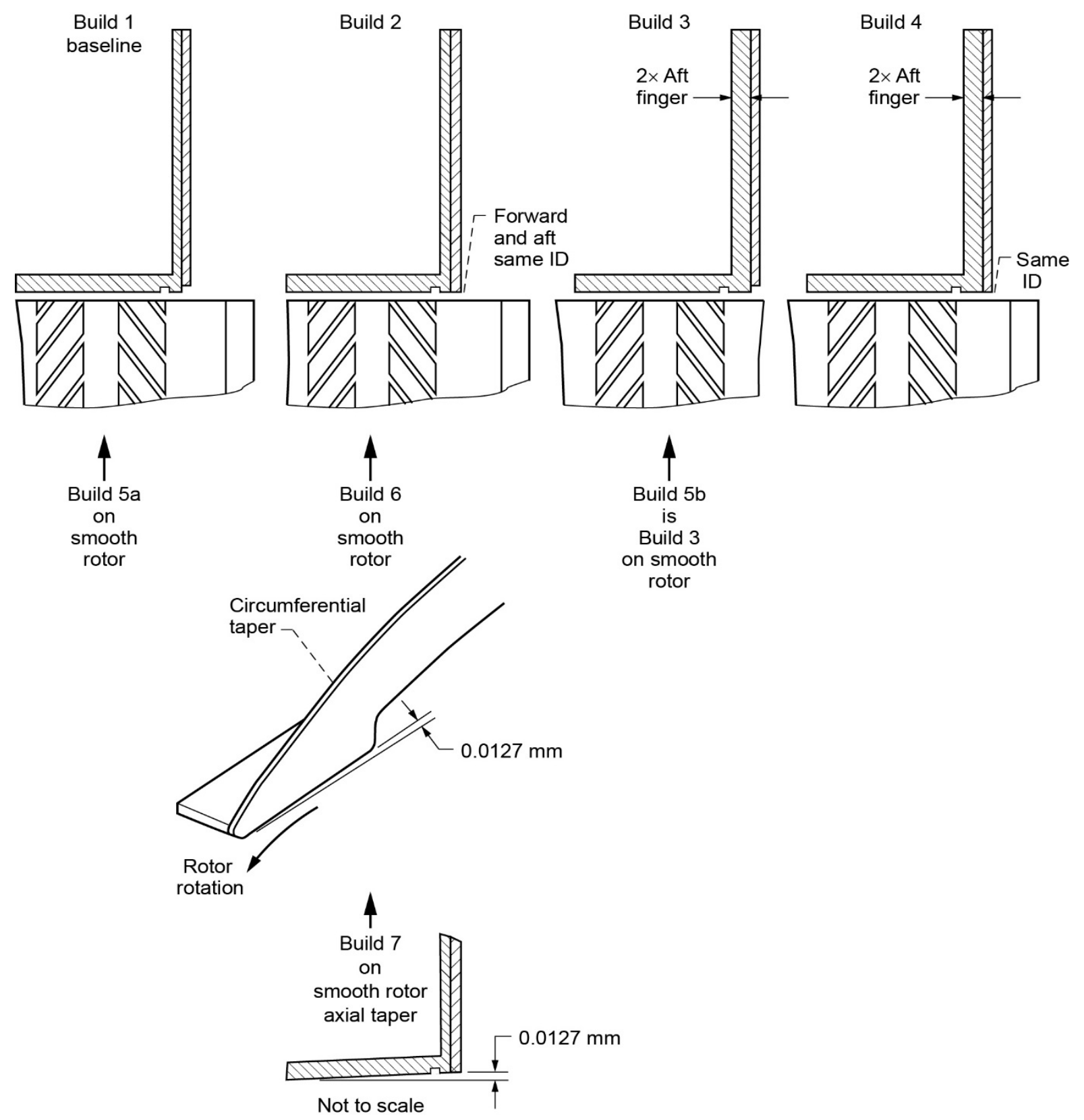

Figure 3. Graphical illustration of the differences in Builds 1 to 7. 


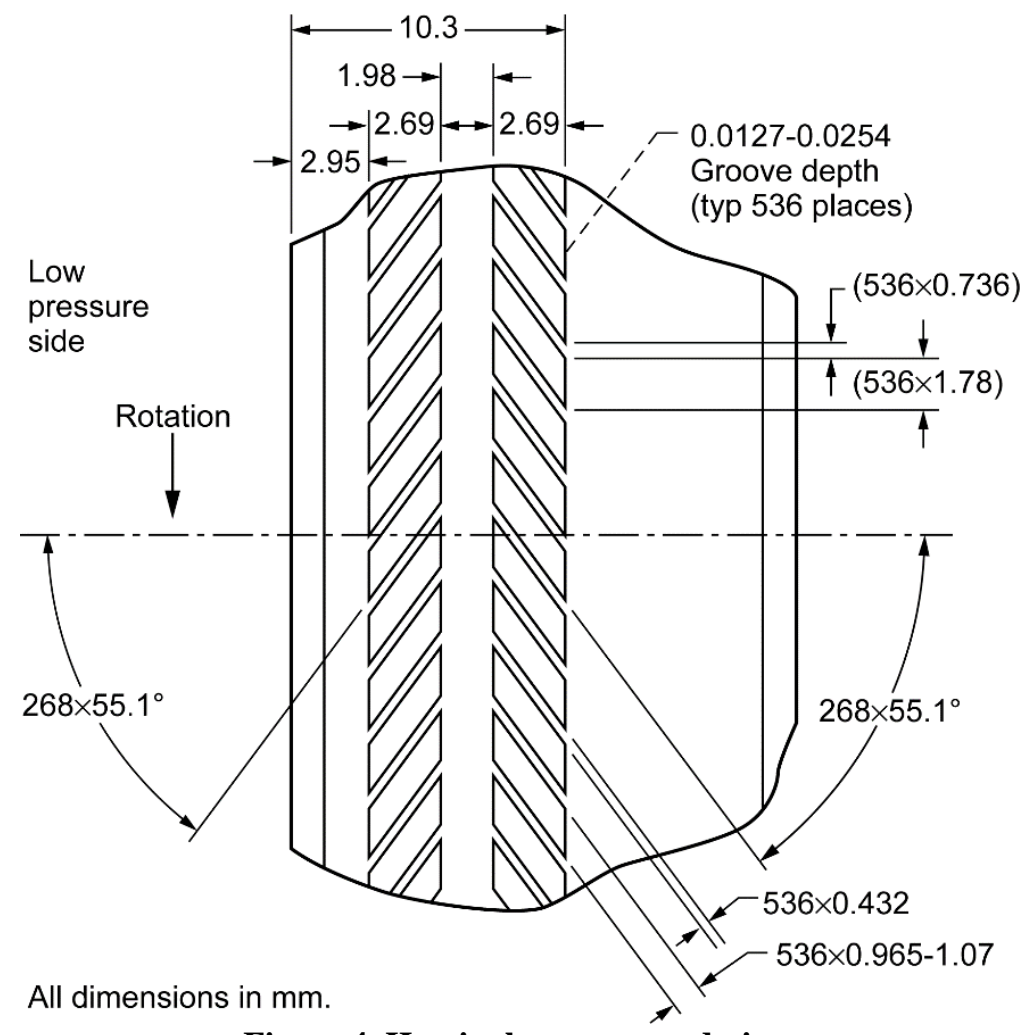

Figure 4. Herringbone groove design.

\section{Test Rotors}

The seal test rotors have an outer diameter of $216 \mathrm{~mm}$ (8.5 in.), nominally, and are made of Grainex Mar-M-247, a nickel-based alloy with excellent high-temperature properties. The seal runner surface on the outer diameter is coated with chrome carbide (CrC) applied by high velocity oxygen fuel thermal spraying (HVOF) and ground to a $0.2 \mu \mathrm{m}$ (8 $\mu \mathrm{in}$.) surface finish. The baseline non-contacting finger seal design uses a rotor with herringbone grooves. The herringbone groove pattern, Figure 4, was machined by plunge electro-discharge machining (EDM) to a design depth of 0.0127 to $0.0254 \mathrm{~mm}$. A pre-test photo of the grooves is shown in Figure 5. Pre-test inspection measurement with a profilometer shows the groove depth was $0.020 \mathrm{~mm}$. The inspected diameters of the rotors are shown in Table 1 along with the resulting radial clearances for each build.

\section{Flow Areas}

The axial length of the seal land on Builds 1 and 2 is $0.84 \mathrm{~mm}$ and on Builds 3 and 4 it is $1.14 \mathrm{~mm}$. A longer seal land creates more resistance to the flow. Therefore, the flow under the lift pads for Builds 3 and 4 should be less than for Builds 1 and 2 due to the longer seal land. Further, the radial clearance between the lift pad and rotor for Builds 3 and 4 is $6.4 \mu \mathrm{m}$ smaller than for Builds 1 and 2, which should also result in lower leakage under the lift pads for Builds 3 and 4 than for Builds 1 and 2.

The pinhole leakage flow rate under the forward fingers and between the aft fingers should be lower for Builds 2 and 4 than for Builds 1and 3 since the radial clearances for the forward fingers are 0.019 and $0.3962 \mathrm{~mm}$, respectively.

The radially inward flow rate through the slots between the fingers at the seal dam should be greatest for Builds 3, 4 and $5 \mathrm{~b}$ since the axial thickness of the aft fingers is approximately double that of Build 1, 2, 5a, 6, and 7.

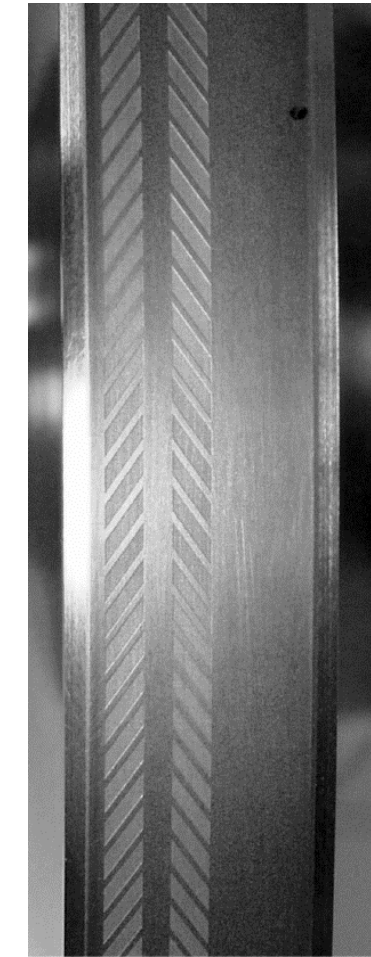

Figure 5. Pre-test photo of herringbone grooves on seal test rotor. 
Table 2. As-built flow areas of the non-contacting finger seals tested.

\begin{tabular}{clcccc}
\hline \hline \multirow{2}{*}{$\begin{array}{c}\text { Build } \\
\text { no. }\end{array}$} & \multicolumn{1}{c}{ Description } & \multicolumn{4}{c}{ Flow areas $\left(\mathrm{mm}^{2}\right)$} \\
\cline { 2 - 5 } & & At seal dam & Pin holes & Under lift pads & Total \\
\hline 1 & Baseline & 13.8 & 13.0 & 15.6 & 42.4 \\
2 & Baseline with same ID & 13.8 & 0.6 & 15.6 & 30.0 \\
3 & Baseline with two times aft finger & 25.5 & 13.0 & 11.5 & 50.0 \\
4 & Two times aft finger and same ID & 25.5 & 0.6 & 11.5 & 37.6 \\
5a & Build 1 on smooth rotor & 13.8 & 12.8 & 9.8 & 36.4 \\
5b & Build 3 on smooth rotor & 25.5 & 12.8 & 5.7 & 44.0 \\
6 & 0.0127 mm circum. taper & 13.0 & 0.3 & 1.6 & 14.9 \\
7 & 0.0127 mm axial taper & 13.0 & 0.3 & 1.6 & 14.9 \\
\hline \hline
\end{tabular}

Table 3. Max to min ranking of as-built flow areas of non-contacting finger seals tested.

\begin{tabular}{cc}
\hline \hline $\begin{array}{c}\text { Build } \\
\text { no. }\end{array}$ & $\begin{array}{c}\text { Total area at build } \\
\left(\mathrm{mm}^{2}\right)\end{array}$ \\
\hline 3 & 50.0 \\
$5 \mathrm{~b}$ & 44.0 \\
1 & 42.4 \\
4 & 37.6 \\
$5 \mathrm{a}$ & 36.4 \\
2 & 30.0 \\
6 & 14.9 \\
7 & 14.9 \\
\hline \hline
\end{tabular}

For each seal, the sum of the flow rates through these 3 flow paths is the total flow through the seal. The question is, which of these flow paths is dominate? To address this, one can look at the areas and the percentage of the total areas. See Table 2, which shows the flow areas of the 3 different leakage paths at build. The areas at the seal dam are not expected to change when pressure differential is applied to the seal. The areas of the pinholes and under the lift pads will decrease as pressure differential is applied and the fingers are drawn radially inward. So it is reasonable to assume the leakage flow rate will not be any less than the flow going through slots at the seal dam. Table 3 ranks the builds from highest to lowest flow areas. Assuming the finger pads remain concentric to the rotor, the fingers don't deflect downstream, and the herringbone grooves don't affect the static leakage rate, then one may expect the leakage performance of the builds to have the same ranking.

\section{Test Apparatus}

\section{A. Turbine Seal Test Rig}

Testing was conducted in the NASA High-Temperature, High-Speed Turbine Seal Test Rig shown in Figure 6 and located at the Glenn Research Center in Cleveland, Ohio. The turbine seal test rig consists of a 216-mm diameter test rotor mounted on a shaft in an overhung configuration. The shaft is supported by two oil-lubricated bearings. A balance piston controls the axial thrust load on the bearings due to pressure loads on the test rotor. An air turbine drives the test rig. A torquemeter is located between the air turbine and the test rig and is connected to each by a quill shaft. The test seal is clamped into the Grainex Mar-M-247 seal holder as shown in Figure 7. A C-seal located at the seal holder/test seal interface prevents flow from bypassing the test seal at its outer diameter. The seal holder is heated to approximately match the thermal growth of the rotor and prevent a damaging change in radial clearance. Heated, filtered air enters the bottom of the test rig and passes through an inlet plenum that directs the heated air axially toward the seal-rotor interface. The hot air either leaks through the test seal to the seal exhaust line or exits the rig before the test seal through a controlled bypass line at the top of the rig. If seal leakage is low, the bypass line must be open to maintain sufficient flow through the test rig to keep the rig hot. 


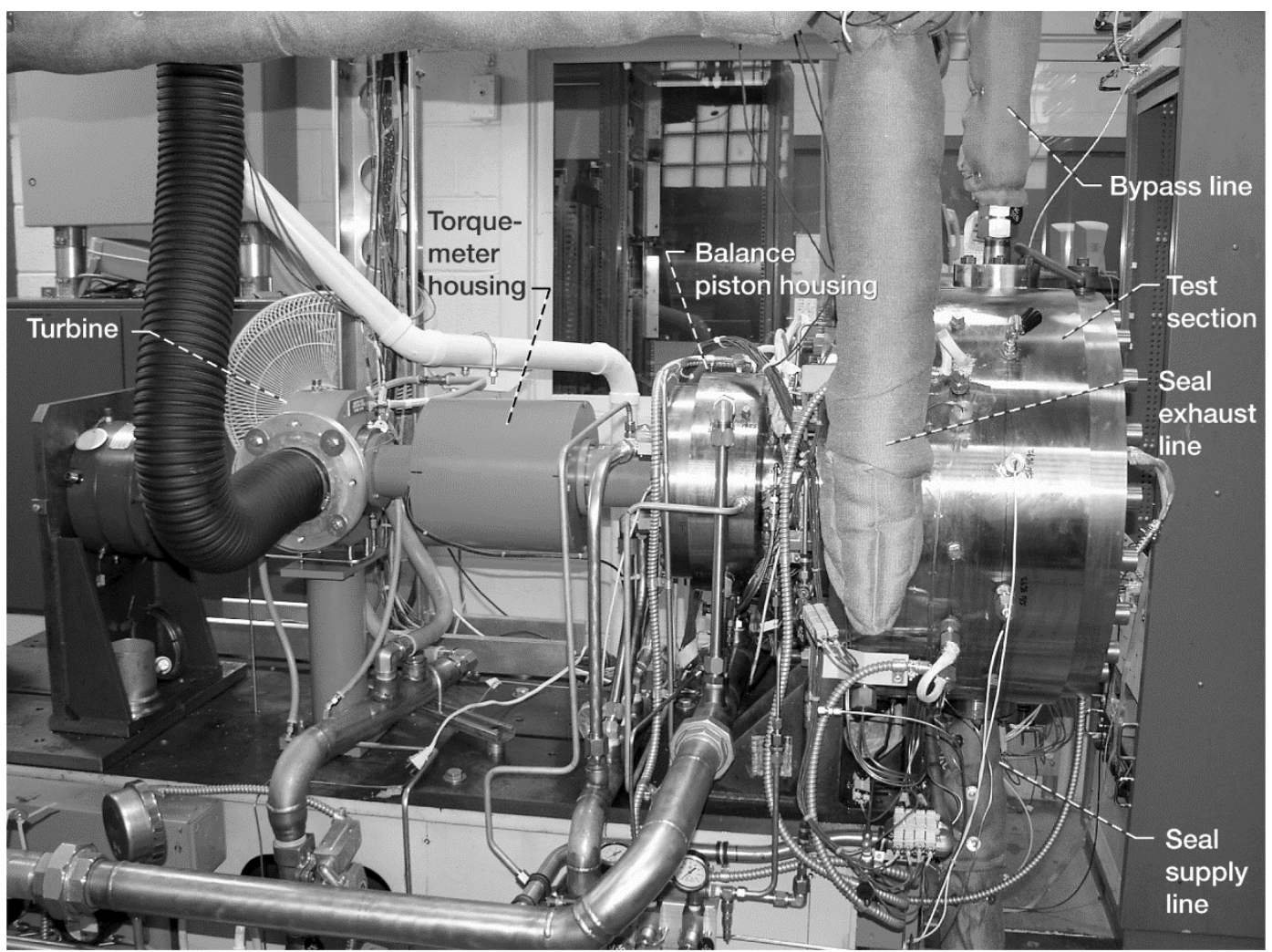

Figure 6. High-temperature, high-speed turbine seal rig.

\section{B. Instrumentation}

Seal inlet and exit temperatures and static pressures, seal upstream metal temperature, and seal backface temperatures were measured at the locations shown in Figure 7. For each measurement there were three probes equally spaced around the circumference, except for the upstream seal metal temperature for which two thermocouples were located at the $90^{\circ}$ and $180^{\circ}$ positions $\left(0^{\circ}\right.$ is top dead center). Type- $\mathrm{K}$ thermocouples with Inconel sheath were used. Those used to measure the seal inlet air temperature were $1.57 \mathrm{~mm}$, closed ball and those used to measure the seal exit air temperature were $3.2 \mathrm{~mm}$, closed-ball. The thermocouples used to measure the seal metal and the seal backface temperatures were $1.57 \mathrm{~mm}$, open-ball.

Venturi flow meters were used to measure the flow rates of the hot air supplied to the rig and the air exiting the rig through the bypass line. The seal leakage rate is the difference between these two flow measurements and is

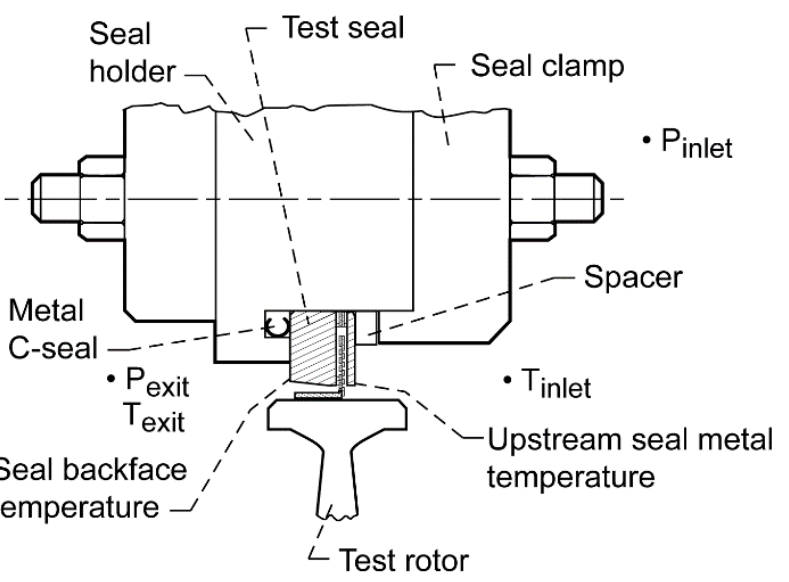

Figure 7. Test seal configuration and location of research measurements. used to calculate the flow factor, which is defined as:

$$
\Phi=\frac{\dot{m} \sqrt{T_{\text {avg }}}}{P_{u} \times D_{\text {seal }}}
$$


The flow factor can be used to compare the leakage performance of seals with different diameters and with different operating conditions. The accuracy of the measured flow factor is \pm 1.5 percent.

\section{Test Procedure}

The test sequence for each build of the non-contacting finger seals was to conduct a room temperature static test, a bind-up test, repeat room temperature static test, static test with bigger clearance, static test at $533 \mathrm{~K}$, static test at $700 \mathrm{~K}$, and static test at $922 \mathrm{~K}$. This was the test sequence for Builds 1 to 4, 6, and 7. Only the room temperature static test, bind-up test, and repeat room temperature static test were conducted for Builds $5 \mathrm{a}$ and $5 \mathrm{~b}$.

\section{A. Room Temperature Static Test (Initial and Repeat)}

At zero rpm and room temperature air, data was recorded at pressure differentials across the seal of $0,13.8,27.6$, 41.4, 55.2, 68.9, 103.4, 137.9, 172.4, 206.8, 275.8, 344.7, 413.7, 517, 552, 621, $689.5 \mathrm{kPa}$. Each pressure condition was held for approximately 30 to $60 \mathrm{sec}$. The pressure ramp up and down was repeated twice for a total of 3 cycles.

\section{B. Bind-Up Test}

The bind-up test was also conducted at room temperature. The end cap on the turbine drive was removed to access the drive shaft. Starting at $0 \mathrm{kPa}$ across the seal and at incremental steps of $14 \mathrm{kPa}$, a wrench was placed on the turbine nut and used to check the ease of turning the shaft. Once the shaft became difficult to turn by hand, no further attempts to turn the shaft were made to prevent damage to the rotor coating and seal. The pressure was then increased to the maximum differential to record data at that condition. Then the pressure differential was decreased to $0 \mathrm{kPa}$. Data were recorded at each step of pressure differential and in some cases data were continuously recorded throughout the test.

\section{Static Test with Bigger Clearance}

A static test with a bigger clearance was conducted by flowing ambient air to the seal at a constant pressure differential and turning on the heaters in the seal holder, thus changing the seal clearance. Data were continuously recorded, however are not discussed in this paper.

\section{Static Tests at 533,700 , and $922 \mathrm{~K}$}

These tests were conducted in the same fashion as the room temperature static tests, except that the inlet air temperature and seal holder temperature were set to 533, 700, and $922 \mathrm{~K}$, respectively. It should be noted that the rig had to be heated to these conditions, which requires substantial air flow and time. Once test conditions were achieved, the pressure differential across the seal was reduced to zero and held for approximately 1 minute to reset the seal before the test began. Doing this caused the inlet air temperature to drop approximately 28 to $56 \mathrm{~K}$. The temperature recovered as the pressure drop across the seal increased. The actual temperature variation is noted in the results.

\section{Test Results and Discussion}

\section{A. Leakage Performance at $294 \mathrm{~K}$}

In reviewing the initial room temperature static performance test data it was found that the flow factor decreased with each cycle of pressure differential increasing and decreasing. It was also observed that the flow factors for each pressure differential increase/decrease cycle in the repeat room temperature static test were in much better agreement compared to the initial test. Presumably, this is the result of the pressure cycles and hand rotation during the bind-up test helping the fingers to move into better position. Consequently, the initial room temperature performance test results will not be presented.

The repeat room temperature static performance test results are shown in Figure 8 to Figure 15 for Builds 1, 2, 3, 4, 5a, 5b, 6, and 7, respectively, which show the measured flow factor as a function of the pressure drop across the seal. In all cases, there is hysteresis between the increasing and decreasing pressure differential portions of each cycle. The flow factor is higher when the pressure is being increased than when it is being decreased. This is because the pressure pushes the seal closed and frictional forces hold it in that position. The pressure differential must be reduced to zero to release the seal position. Note that the flow factors level out at pressure differentials above approximately $90 \mathrm{kPa}$, which indicates choked flow. 


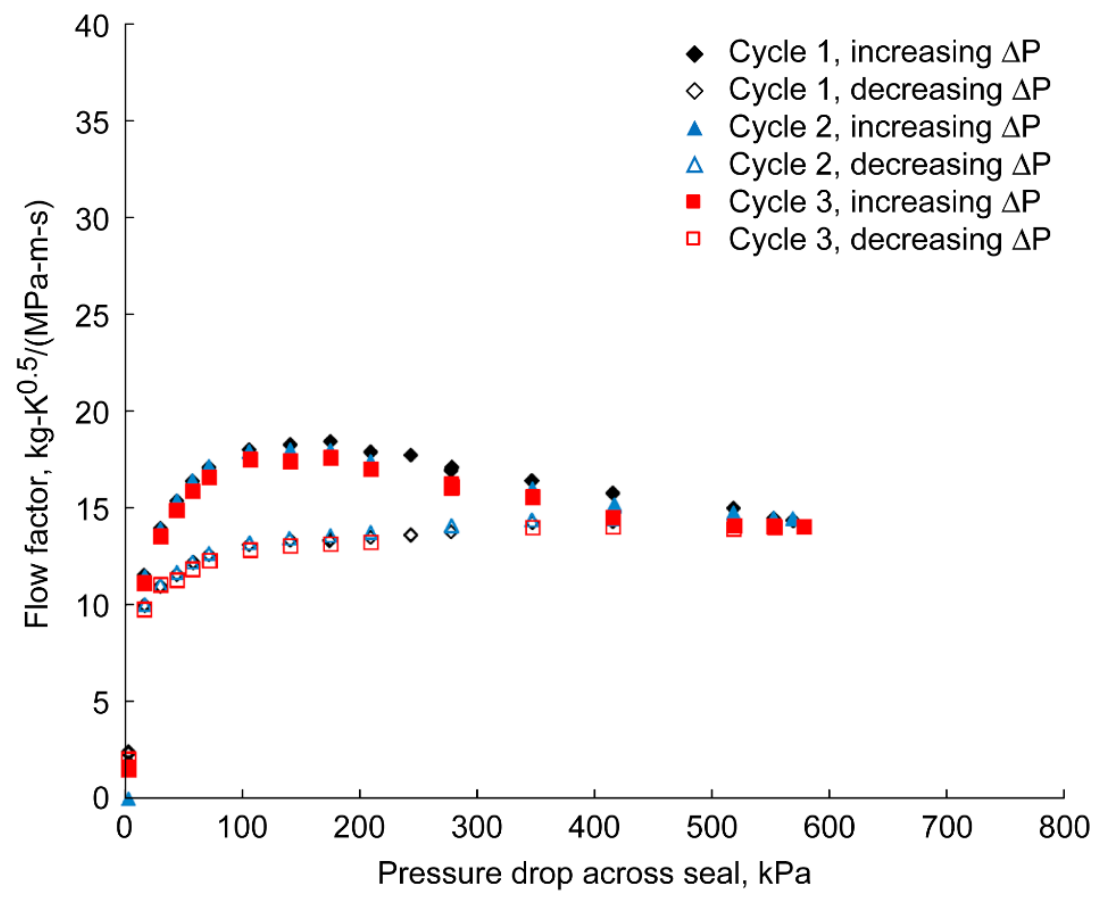

Figure 8. Static leakage performance of baseline non-contacting finger seal Build 1 at 276 to $294 \mathrm{~K}$ average inlet air temperature.

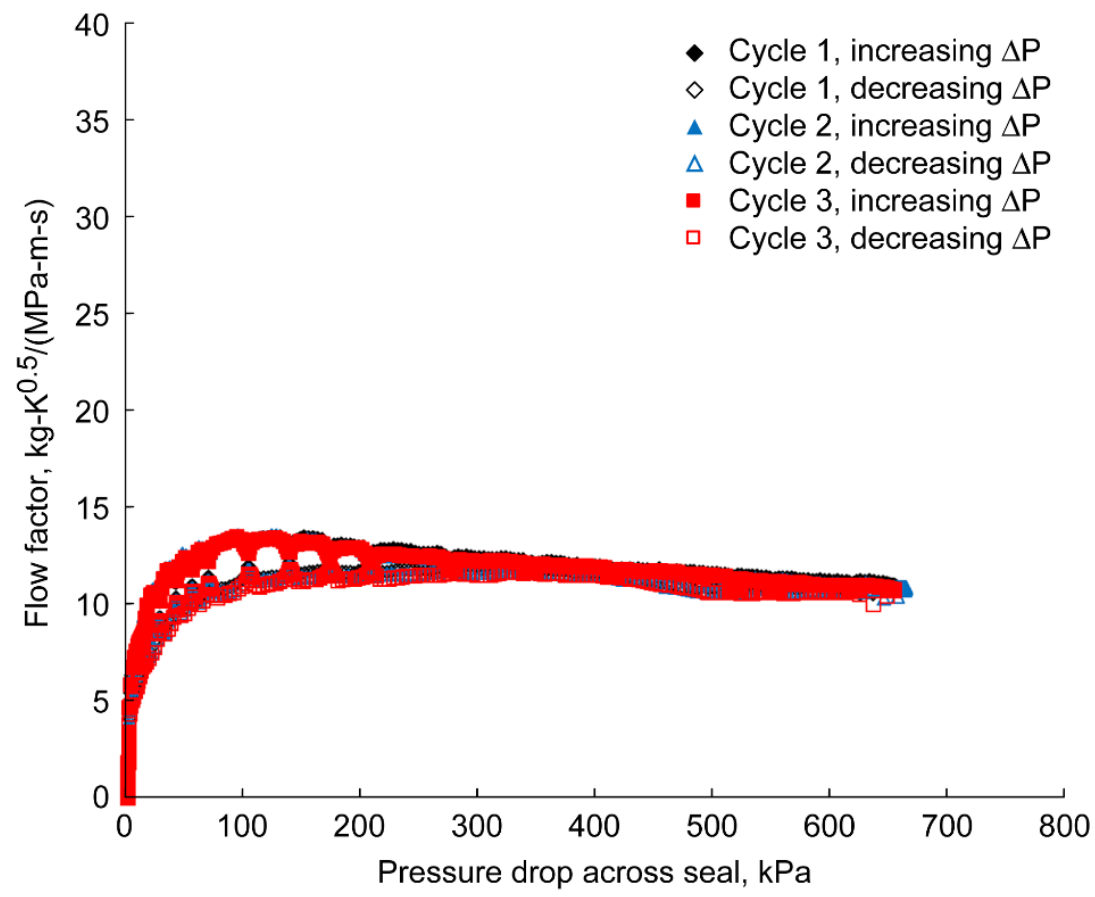

Figure 9. Static leakage performance of non-contacting finger seal Build 2 at 297 to $299 \mathrm{~K}$ average inlet air temperature. 


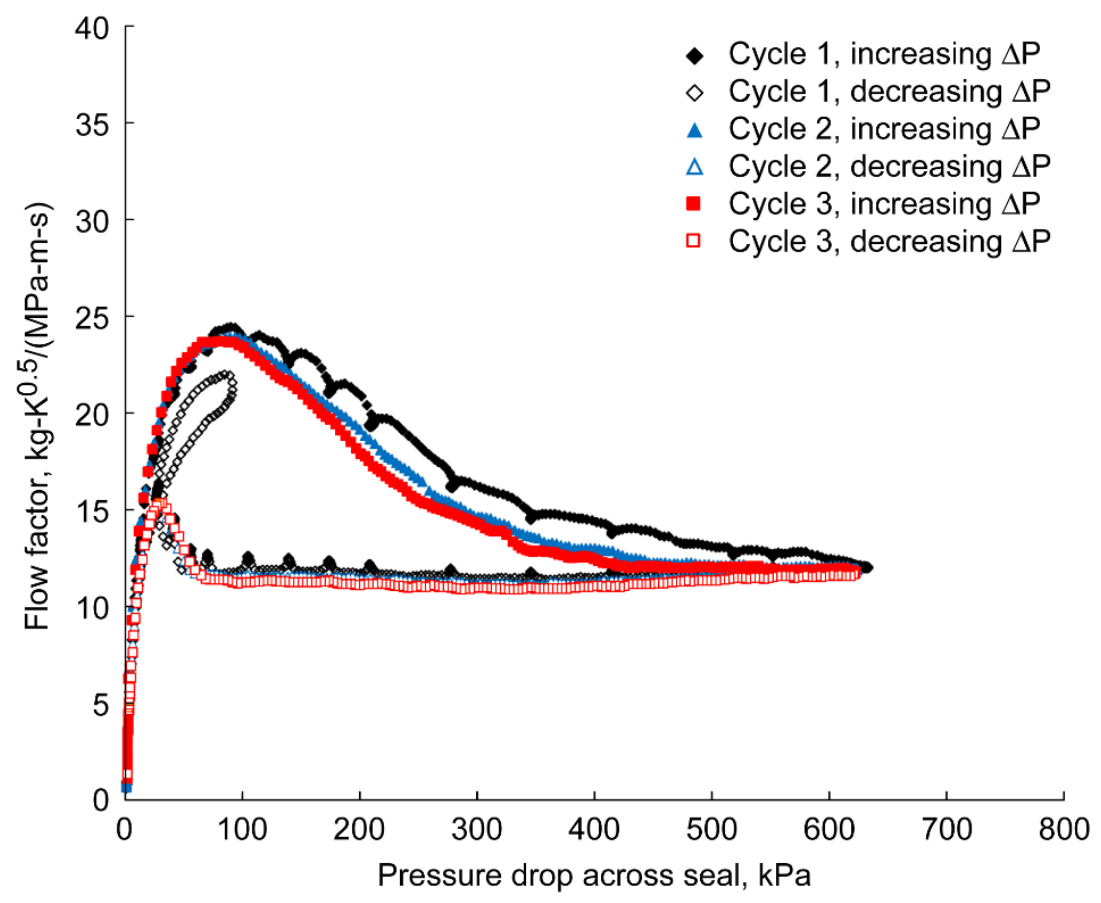

Figure 10. Static leakage performance of non-contacting finger seal Build 3 at 301 to $303 \mathrm{~K}$ average inlet air temperature.

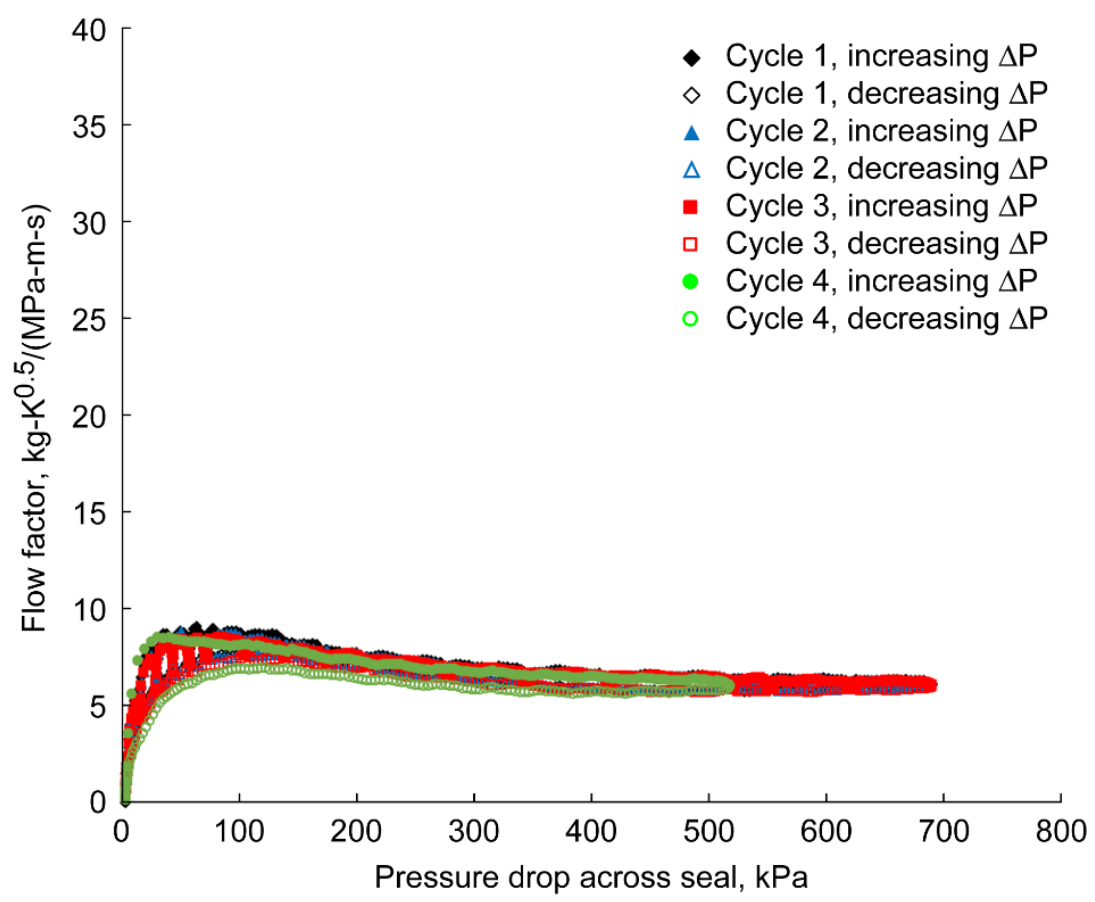

Figure 11. Static leakage performance of non-contacting finger seal Build 4 at 303 to $304 \mathrm{~K}$ average inlet air temperature. 


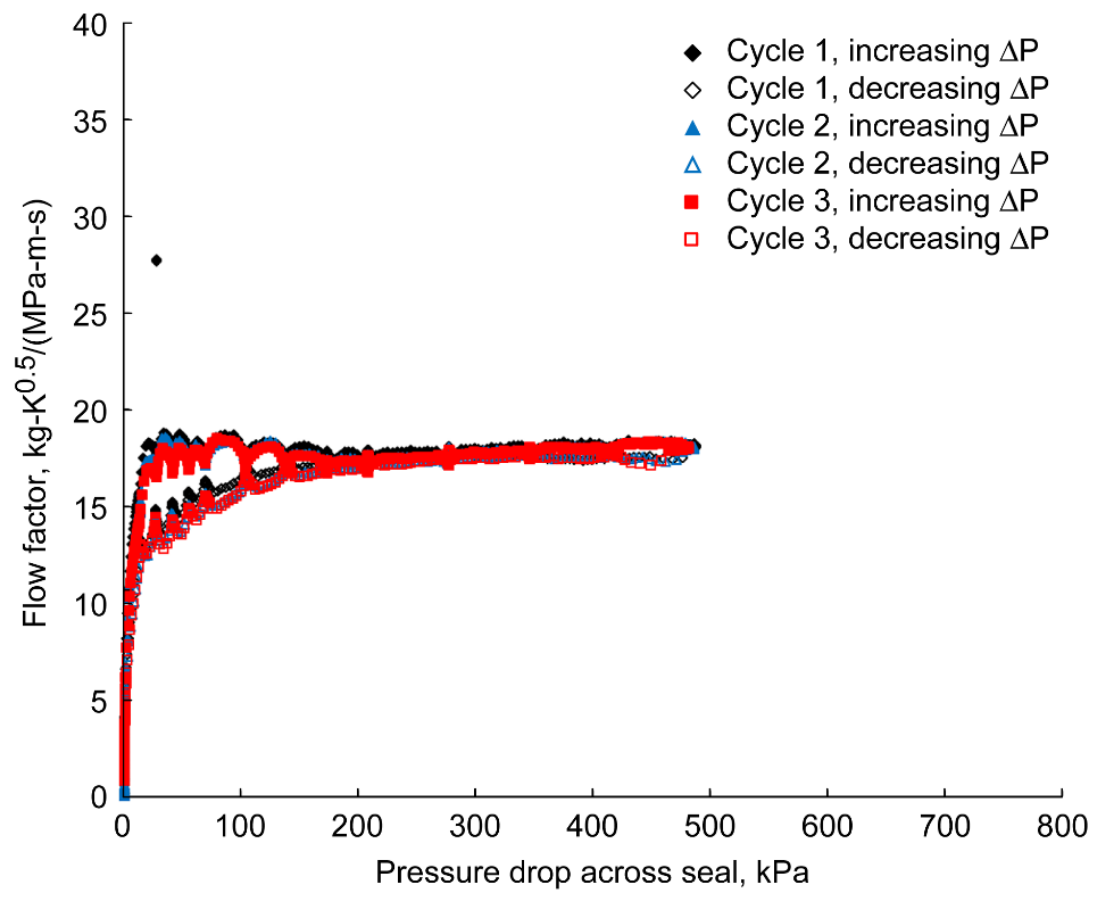

Figure 12. Static leakage performance of non-contacting finger seal Build $5 \mathrm{a}$ at 280 to $292 \mathrm{~K}$ average inlet air temperature.

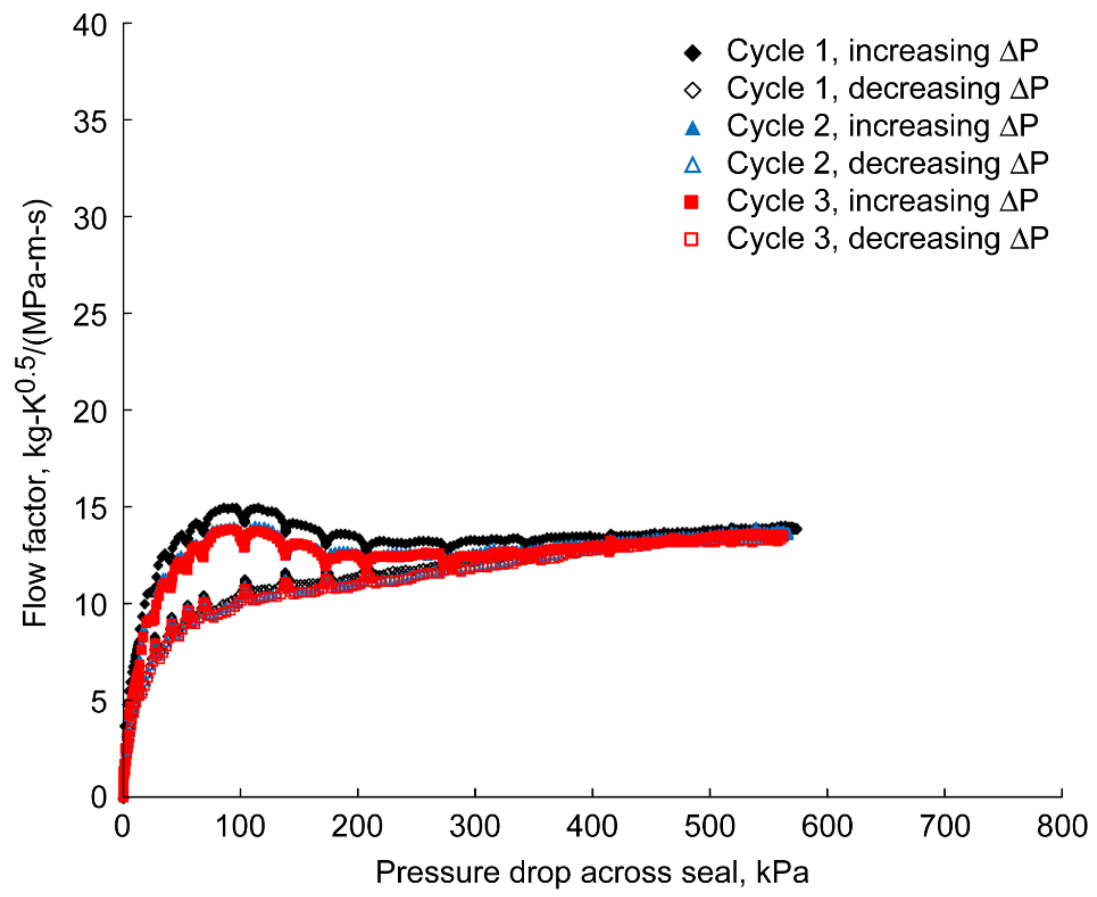

Figure 13. Static leakage performance of non-contacting finger seal Build $5 \mathrm{~b}$ at 282 to $289 \mathrm{~K}$ average inlet air temperature. 


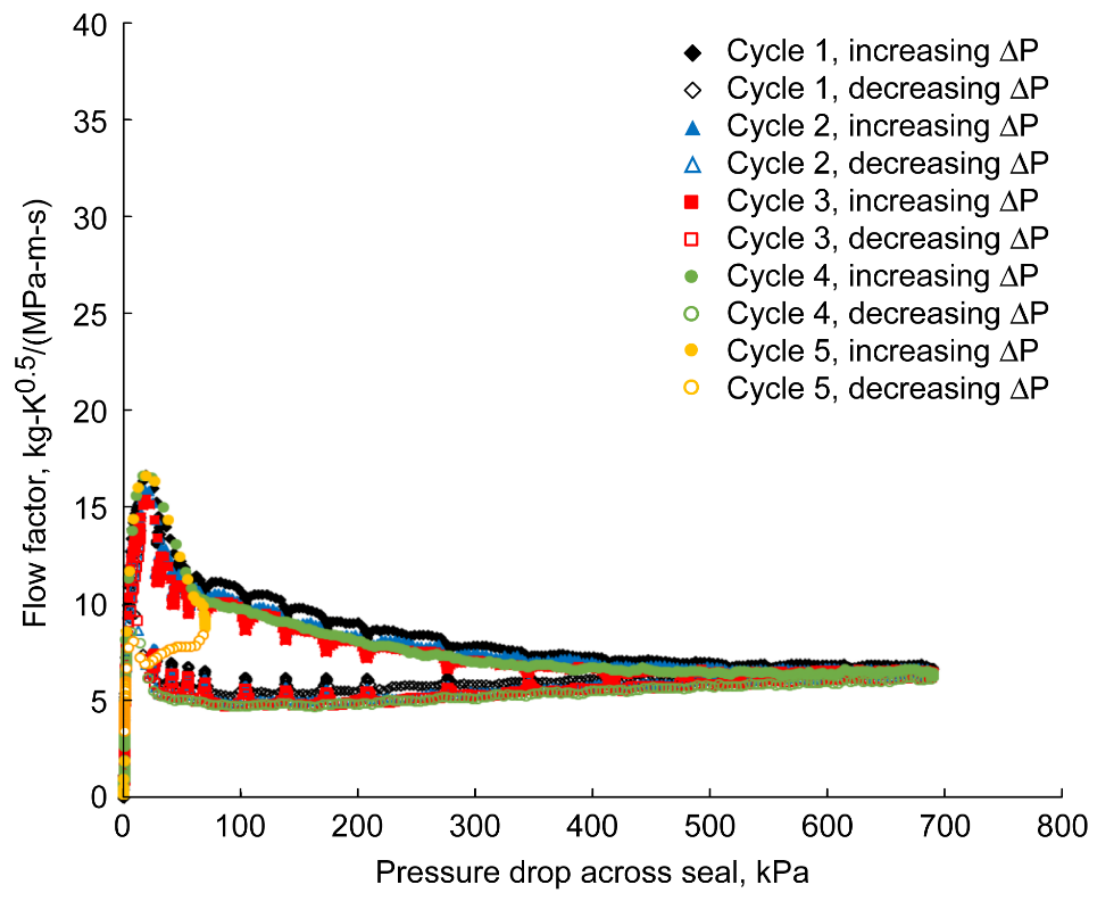

Figure 14. Static leakage performance of non-contacting finger seal with circumferential taper, Build 6, at 283 to $294 \mathrm{~K}$ average inlet air temperature.

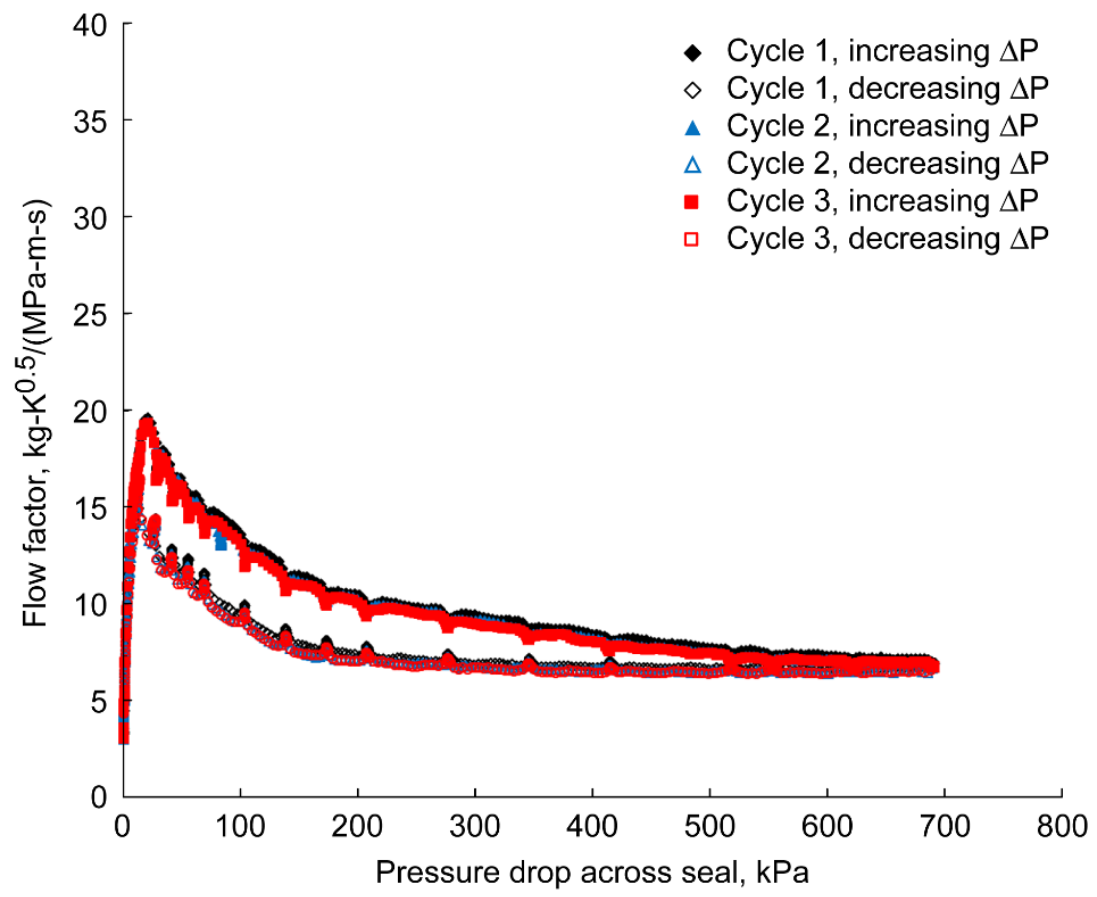

Figure 15. Static leakage performance of non-contacting finger seal with axial taper on lift pad, Build 7, at 275 to $298 \mathrm{~K}$ average inlet air temperature. 
Table 4. Summary of static leakage performance flow factors of non-contacting finger seal Builds 1 to 7 at ambient, 533, 700, and $922 \mathrm{~K}$.

\begin{tabular}{|c|c|c|c|c|c|}
\hline $\begin{array}{c}\text { Build } \\
\text { no. }\end{array}$ & $294 \mathrm{~K}$ & $2533 \mathrm{~K}$ & $700 \mathrm{~K}$ & $922 \mathrm{~K}$ & Parameter \\
\hline 1 & 18.4 & 25.7 & 26.6 & 27.4 & $\phi_{\max }$ \\
\hline 1 & 14 & $20-25$ & 19.8 & 21 & $\phi_{\text {leveled }}$ \\
\hline 1 & $276-294$ & 508-685 & 664-709 & $867-925$ & $T_{\text {avg }}$ \\
\hline 2 & 13.5 & 20.4 & 23.7 & 24 & $\phi_{\max }$ \\
\hline 2 & 10.6 & 14.4 & 17.7 & 17.5 & $\phi_{\text {leveled }}$ \\
\hline 2 & 297-299 & 520-549 & 665-697 & $867-907$ & $T_{a v g}$ \\
\hline 3 & 24.4 & 23.4 & 27.3 & 37.7 & $\phi_{\max }$ \\
\hline 3 & 10.9 & 19.2 & $21-21.5$ & $23,25.7$ & $\phi_{\text {leveled }}$ \\
\hline 3 & 301-303 & 525-559 & $671-706$ & 852-923 & $T_{\text {avg }}$ \\
\hline 4 & 9 & 16.3 & 18.5 & 25.5 & $\phi_{\max }$ \\
\hline 4 & 5.7 & 9.5 & 12.6 & 15.8 & $\phi_{\text {leveled }}$ \\
\hline 4 & 303-304 & $530-616$ & 683-719 & 862-911 & $T_{a v g}$ \\
\hline $5 a$ & $18.8-27.7$ & ---------- & ---------- & --------- & $\phi_{\max }$ \\
\hline $5 a$ & 17.5 & ---------- & --------- & ---------- & $\phi_{\text {leveled }}$ \\
\hline $5 a$ & $280-292$ & -------- & -------- & --------- & $T_{a v g}$ \\
\hline $5 b$ & 15 & --------- & --------- & --------- & $\phi_{\max }$ \\
\hline $5 b$ & 13.2 & ---------- & --------- & --------- & $\phi_{\text {leveled }}$ \\
\hline $5 b$ & $282-289$ & ---------- & --------- & --------- & $T_{a v g}$ \\
\hline 6 & 16.6 & 26.5 & 27.9 & 31.1 & $\phi_{\max }$ \\
\hline 6 & 4.8 & 11.1 & 9.6-10.6 & 16.8 & $\phi_{\text {leveled }}$ \\
\hline 6 & 283-294 & $537-641$ & 663-697 & 859-921 & $T_{a v g}$ \\
\hline 7 & 21.7 & 28.3 & 29.3 & 33.3 & $\phi_{\max }$ \\
\hline 7 & 6.9 & 11.6 & 11.5 & 16.2 & $\phi_{\text {leveled }}$ \\
\hline 7 & $275-298$ & 546-605 & 673-704 & 866-908 & $T_{a v g}$ \\
\hline
\end{tabular}

Table 4 shows the measured maximum flow factor and the value at which it levels out for each build and inlet air temperature. For all builds, the flow factor increases with increased average seal inlet air temperature. This is due to the seal material having a higher coefficient of thermal expansion than the rotor material, which results in the radial seal clearance increasing with temperature. For example, if the seal and rotor interface was a line-to-line fit at $215.9 \mathrm{~mm}\left(8.5 \mathrm{in}\right.$.) diameter at $294 \mathrm{~K}\left(70^{\circ} \mathrm{F}\right)$, a temperature increase to $700 \mathrm{~K}\left(800^{\circ} \mathrm{F}\right)$ would result in $0.0356 \mathrm{~mm}$ (0.0014 in.) of radial clearance.

Comparing the repeat room temperature flow factors for each build results in the following ranking of the builds from highest to lowest maximum flow factor: 3, 7, 5a, 6, 5b, 1, 2, and 4. This does not match the ranking of the flow areas shown in Table 3. The ranking of builds from highest to lowest leveled flow factor is 5a, 1, 5b, 3, 2, 7, 4, and 6 and also does not match the ranking of the flow areas in Table 3. This means flow areas in the seal are different from the build geometry when pressure is applied. It is known from previous studies of finger seals that the fingers draw in towards the rotor when pressure is applied. Further, pressure loads may cause the fingers to deflect axially. Both of these deflections would change the flow areas and affect the concentricity of the lift pads to the rotor.

Comparison of Build 1 and Build 2 seal leakage performance, Figure 8 and Figure 9, respectively, show the effect of blocking the pinholes between the aft fingers and, as expected, the flow factor for Build 2 is less than that of Build 1. Also, Build 2, which nearly completely blocks the gaps between the aft fingers, has less hysteresis than Build 1. Similarly, by comparing Figure 10 and Figure 11, one can see Build 4, which also nearly completely blocks the gaps between the aft fingers, has lower leakage and less hysteresis than Build 3.

The effect of the axial thickness of the aft finger on leakage performance can be seen by comparing the leakage performance of Build 3 to Build 1, Figure 10 and Figure 8, respectively. Build 3, which has an axial aft finger thickness nearly twice that of Build 1, shows much more leakage and hysteresis at the lower pressure differentials. However, for decreasing pressure differential, the Build 3 flow factor was less than that measured for Build 1. In Figure 10, the 
peak at $\sim 35 \mathrm{kPa}$ when decreasing the pressure differential for Build 3 is of particular interest. Also, the loop in cycle 2 resulted from an operator error that increased pressure differential when it should have been further decreased. Having an aft finger axial thickness nearly double that of Build 1, the Build 3 aft finger radial stiffness is twice that of Build 1 and the axial stiffness is eight times greater. This greater finger stiffness may explain the Build 3 behavior. As pressure is first applied, the higher stiffness of Build 3 fingers would more greatly resist the pressure closing force than Build 1 and result in higher flow factors. Once the pressure load moves the fingers to their closed or bound position, frictional forces hold them in place. When the pressure is then decreased to the point that frictional forces are overcome, the higher spring rate of the finger causes a greater opening of the seal. The lower flow factor while decreasing pressure differential may be attributed to the smaller radial clearance for the aft finger in Build 3 compared to Build 1. The at-build radial clearance of the aft finger is $6.35 \mu \mathrm{m}$ smaller for Build 3 than Build 1. Additionally, the axial length of the seal land on the lift pads of Build 3 is 1.36 times that of Build 1. From laminar flow theory it is known that the mass leakage rate is inversely proportional to the length of the seal land. So the seal with the longer land would leak less.

Comparing the leakage performance of Build 2 to Build 4, Figure 9 and Figure 11, respectively, also should reveal the effect of the aft finger axial thickness on leakage performance. Similar to the comparison of Builds 3 and 1 , the at-build radial clearance of the aft finger is $6.35 \mu \mathrm{m}$ smaller for Build 4 than Build 2; the aft axial finger thickness of Build 4 is nearly twice that of Build 2; and the axial length of the seal land on the lift pads of Build 4 is 1.36 times that of Build 2. Noting that the total flow area (Table 2) for Build 4 is greater than for Build 2, one would expect the flow factors for Build 4 to be greater than those for Build 2. In fact, the data shows the opposite. This result is attributed to the smaller aft finger radial clearance and longer seal land of Build 4. Further, the greater stiffness of the aft fingers likely reduces axial deflections or twisting that could change the flow area.

It is easy to see the effect of the forward finger inner diameter on the leakage performance by comparing the leveled flow factors for the room temperature repeat static tests for Build 1 to Build 2 and Build 3 to Build 4, shown in Table 4. In both cases, the seal with the forward finger inner diameter nearly the same as the aft finger inner diameter leaked less. For the seals with the baseline aft finger, Builds 1 and 2, the flow factor was reduced 24 percent by reducing the forward finger diameter. For the seals with the thicker aft finger, Builds 3 and 4, the flow factor was reduced 48 percent by reducing the forward finger diameter. This is largely due to reducing the pinhole areas between the aft fingers bounded by the rotor outer diameter and the forward finger inner diameter. Also, by reducing the forward finger inner diameter to nearly the aft finger diameter, the axial leading edges of the aft fingers are exposed to a lower pressure. One could consider the forward fingers as an extension of the seal land, the length of which is inversely proportional to leakage.

Comparing Figure 8 for Build 1 to Figure 12 for Build 5 a gives insight to the effect of the herringbone grooves since Build 5 a is the same seal as Build 1, but on a smooth rotor. Note that the radial clearances for Build 5a are smaller than for Build 1. In spite of this, Build 5a leakage levels out at a higher flow factor than Build 1 and has less hysteresis at about $150 \mathrm{kPa}$ differential pressure than Build 1. The higher flow factors for Build 5a result because the smooth rotor has less resistance compared to the relatively rough herringbone grooves.

Similarly, comparison of the leakage performance of Builds 3 and 5b, Figure 10 and Figure 13, respectively, should give insight into the effect of the herringbone grooves. Again, Build $5 \mathrm{~b}$ has slightly lower radial clearances than Build 3. Build $5 b$ has much less hysteresis than Build 3 . Further, the curve for Build $5 b$ has more slope to it than Build 3 for decreasing pressure differential, and above $275 \mathrm{kPa}$ the flow factor is greater than for Build 3 for decreasing pressure differential. Again, the higher flow factor can be attributed to the reduced flow resistance of the smooth rotor compared to the relatively rough herringbone grooves.

Build 4 leakage performance, Figure 11, shows very little hysteresis and has the lowest flow factor of all the builds. Builds 6 and 7, Figure 14 and Figure 15, respectively, have very similar levels of flow factor above pressure differentials of $300 \mathrm{kPa}$ compared to that of Build 4. However, Builds 6 and 7 leakage performance has more hysteresis and a different curve shape at the lower pressure differentials with a peak at approximately $20 \mathrm{kPa}$. This is surprising since Builds 6 and 7 both have flow areas at-build that are less than half that of Build 4. The peak at low pressure differential suggests that the fingers move away from the test rotor initially. One can be certain that the fingers move with pressure loading and thus change the flow areas. One thing that is different about lift pads of Builds 6 and 7 is that neither has a circumferential groove. Hence, the whole axial length of the lift pad acts as a seal land. The effectiveness of these seal lands is affected by the changing clearance due to the circumferential and axial tapers. 


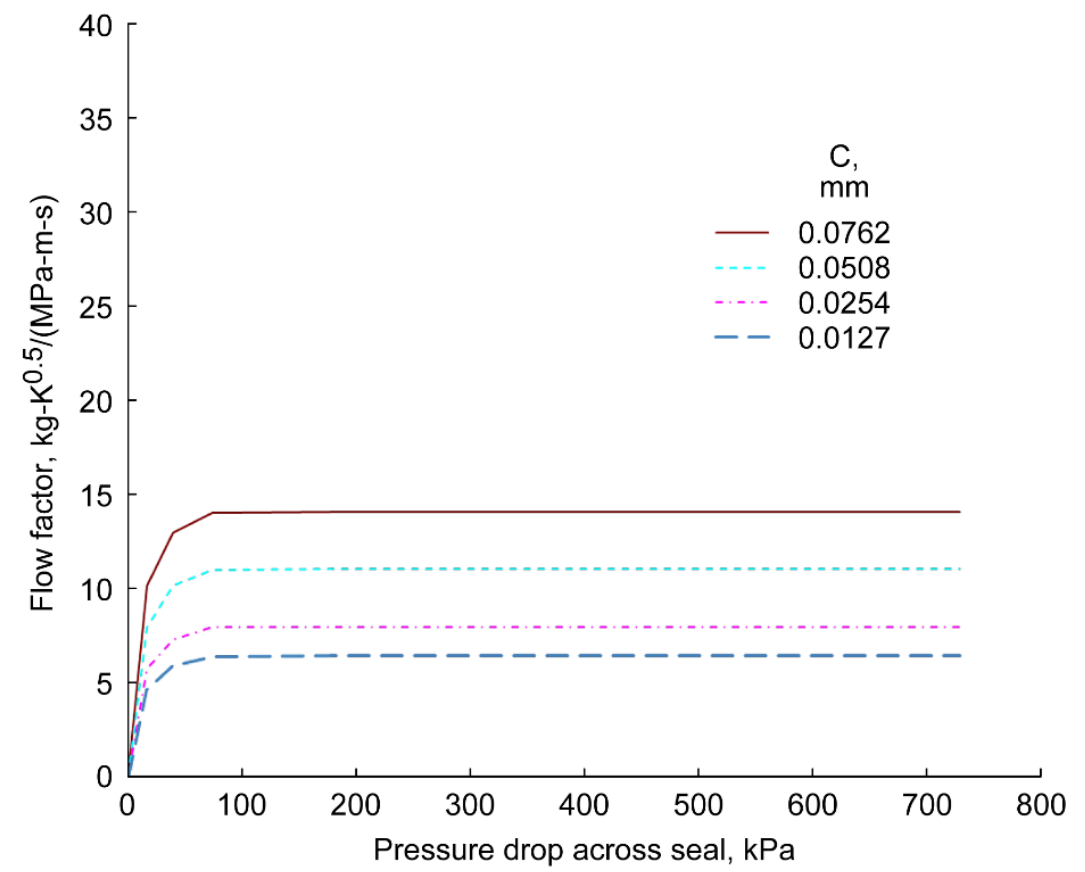

Figure 16. Predicted static leakage performance for non-contacting finger seal Build 4 assuming isentropic choked flow.

Table 5. Predicted flow factors assuming isentropic choked flow for several radial clearances between the lift pad and rotor.

\begin{tabular}{ccccc}
\hline \hline $\begin{array}{c}\text { Build } \\
\text { no. }\end{array}$ & \multicolumn{4}{c}{$\begin{array}{c}\text { Clearance } \\
(\mathrm{mm})\end{array}$} \\
\cline { 2 - 5 } & 0.0127 & 0.0254 & 0.0508 & 0.0762 \\
\cline { 2 - 5 } & \multicolumn{4}{c}{ Predicted flow factors } \\
& \multicolumn{5}{c}{$\left(\mathrm{kg}-\mathrm{K}^{0.5} /(\mathrm{MPa}-\mathrm{m}-\mathrm{s})\right)$} \\
\hline 1 & 6.5 & 8.1 & 11.1 & 14.1 \\
2 & 4.2 & 5.8 & 8.8 & 11.9 \\
3 & 8.7 & 10.2 & 13.3 & 16.4 \\
4 & 6.4 & 8.0 & 11.0 & 14.1 \\
\hline \hline
\end{tabular}

\section{B. Comparison to Predicted Leakage}

Predictions of room temperature leakage performance were made for Builds 1 to 4 using the leakage model described in Ref. 10 and the assumption of isentropic flow. It is also assumed that the geometry is fixed, the lift pads remain concentric to the rotor, and that the fingers are held tightly against each other and the seal dam so that there is no leakage between the contacting areas. The seal radial clearance is an input parameter. The predictions for the Build 4 non-contacting finger seal are shown in Figure 16 and use a discharge coefficient of 1.0. Comparing the predictions to the room temperature static performance results for Build 4, Figure 11, the predicted flow factors for radial clearance of 0.0127 to $0.0254 \mathrm{~mm}$ most closely match the test data. Table 5 shows the choked flow factors for several clearances for each of the Builds 1 to 4 for comparison. It is interesting to note that the predicted flow factors for Build 1 and Build 4 are nearly the same. As expected, Build 3 has the largest predicted flow factor of Builds 1 to 4.

\section{Leakage Performance at $922 \mathrm{~K}$}

The seal leakage performance test results at $922 \mathrm{~K}\left(1200^{\circ} \mathrm{F}\right)$ are shown in Figure 17 to Figure 22 for Builds 1, 2, $3,4,6$ and 7, respectively. In all cases, the flow factor at $922 \mathrm{~K}$ is higher than at room temperature. The shapes of the data curves for Builds 1, 2, 3 and 4 at $922 \mathrm{~K}$ are similar to data taken at room temperature. However, for Builds 6 and 7, Figure 21 and Figure 22, the shape of the curve for decreasing pressure differential is different at $922 \mathrm{~K}$ compared to room temperature data, Figure 14 and Figure 15. Specifically, the flow factor decreases once the pressure differential is reduced lower than $200 \mathrm{kPa}$ rather than tracking the data curve for increasing pressure differential. Explanation of this observation is speculative, but likely is due to clearance changes and thermal effects. 


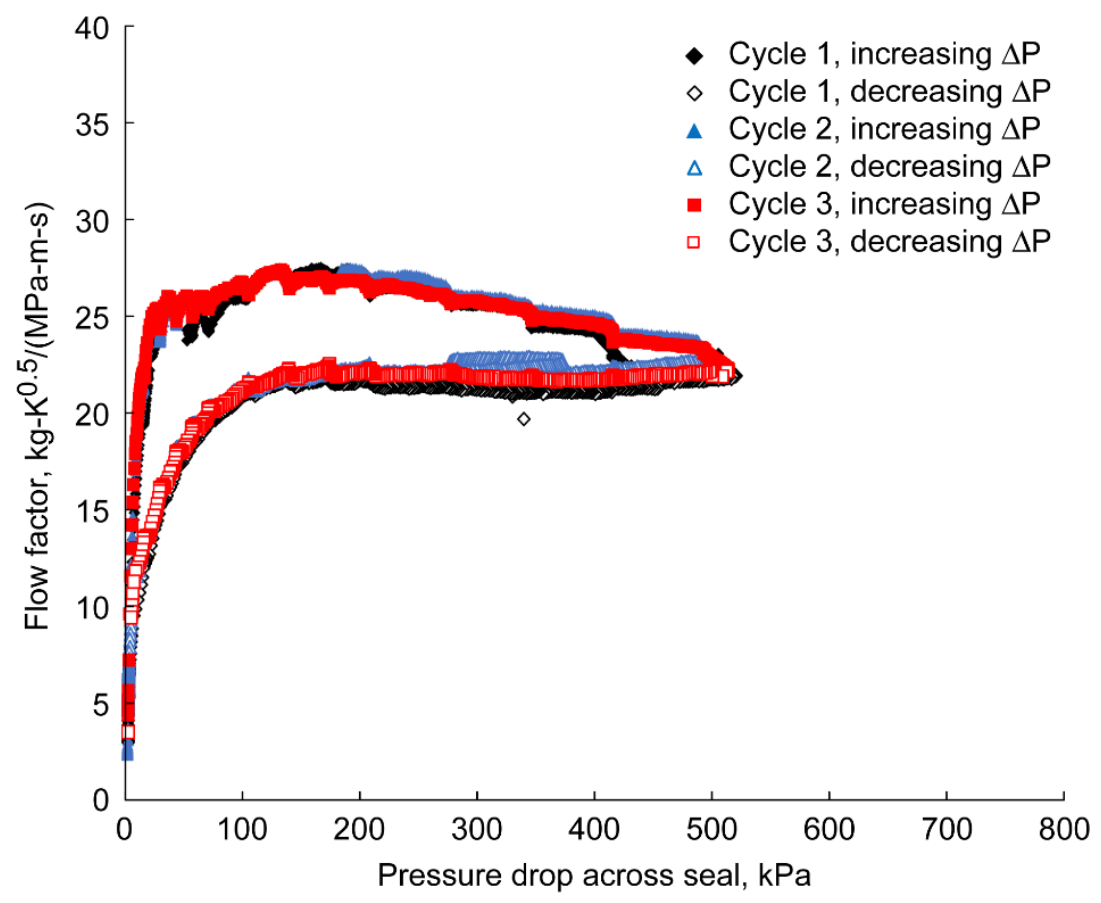

Figure 17. Static leakage performance of baseline non-contacting finger seal Build 1 at 867 to $925 \mathrm{~K}$ average inlet air temperature.

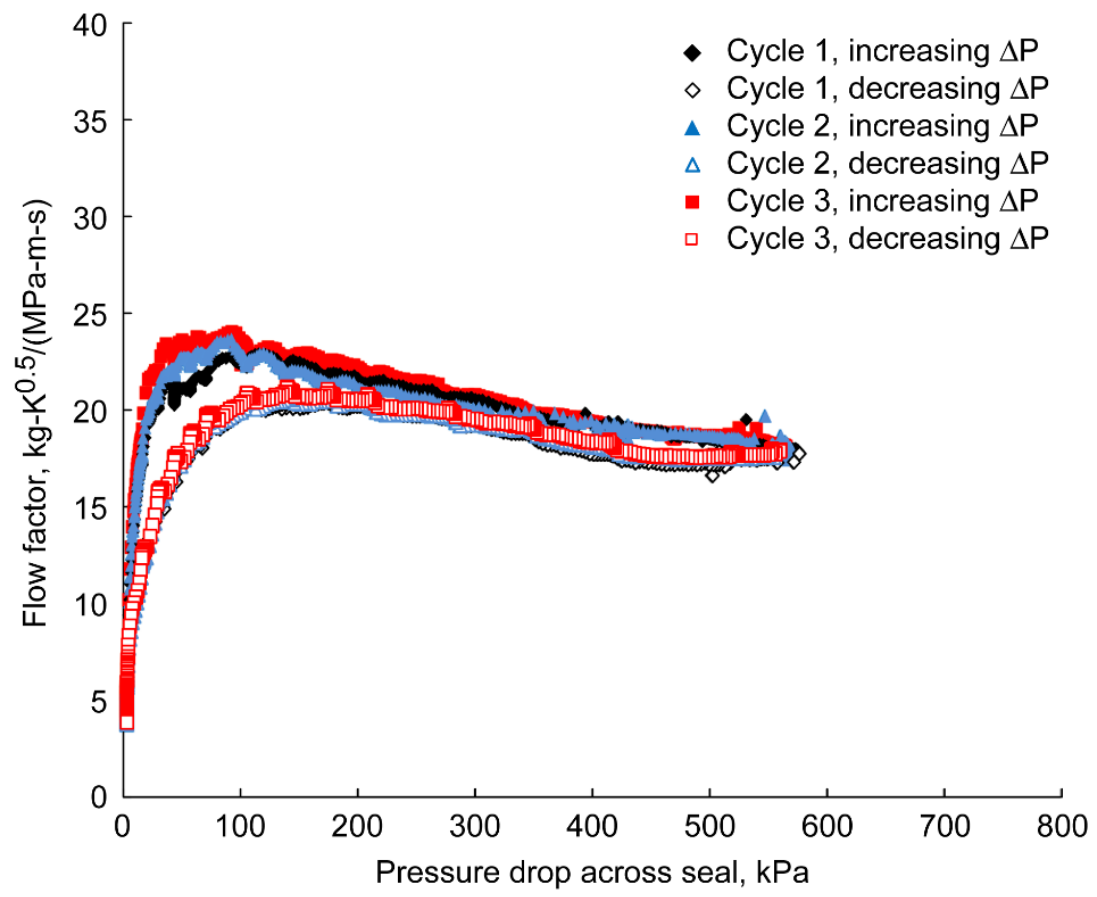

Figure 18. Static leakage performance of non-contacting finger seal Build 2 at 867 to $907 \mathrm{~K}$ average inlet air temperature. 


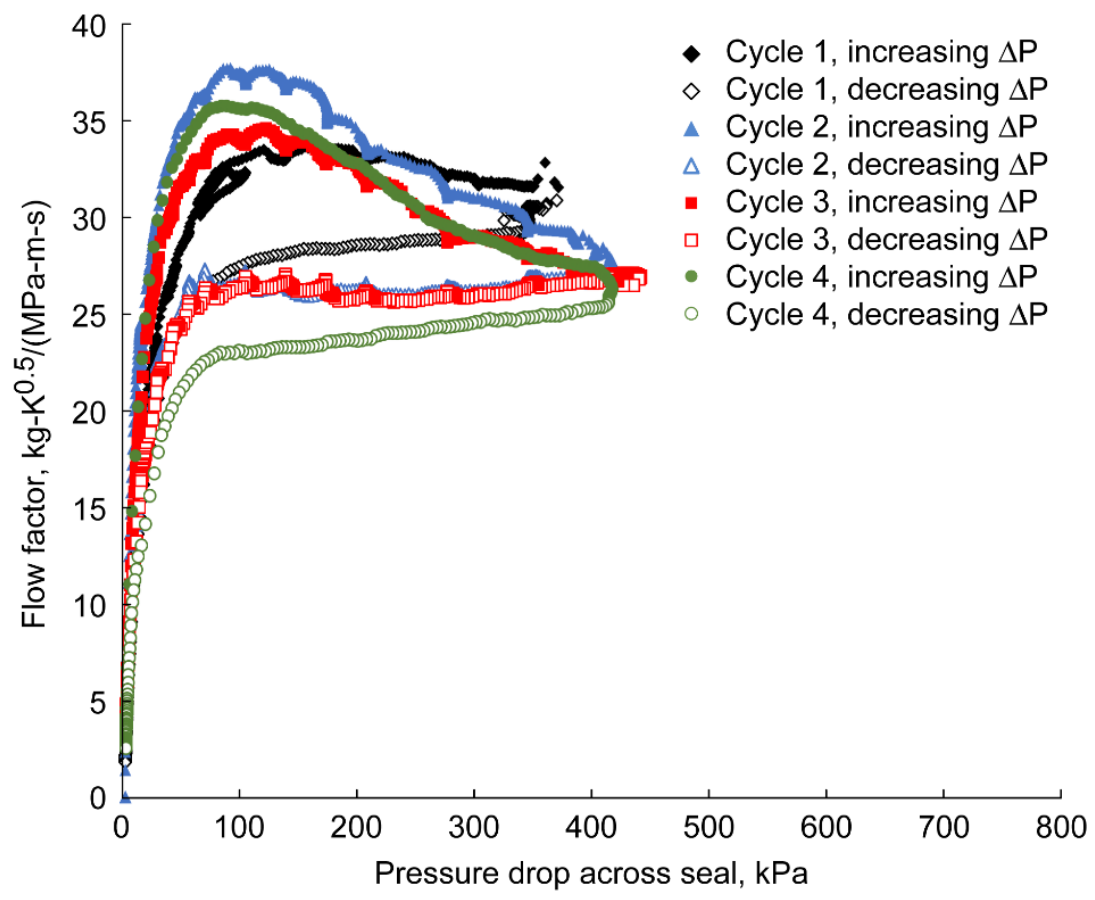

Figure 19. Static leakage performance of non-contacting finger seal Build 3 at 852 to $923 \mathrm{~K}$ average inlet air temperature.

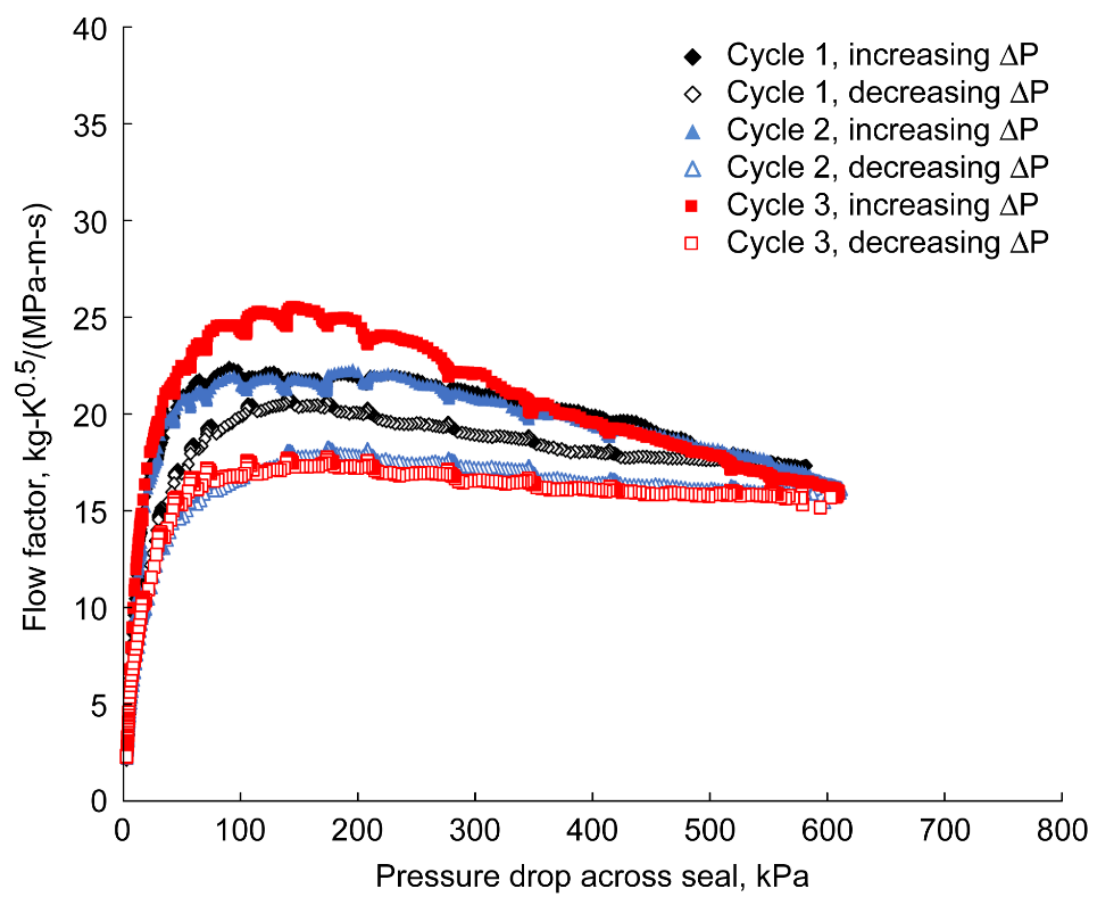

Figure 20. Static leakage performance of non-contacting finger seal Build 4 at 862 to $911 \mathrm{~K}$ average inlet air temperature. 


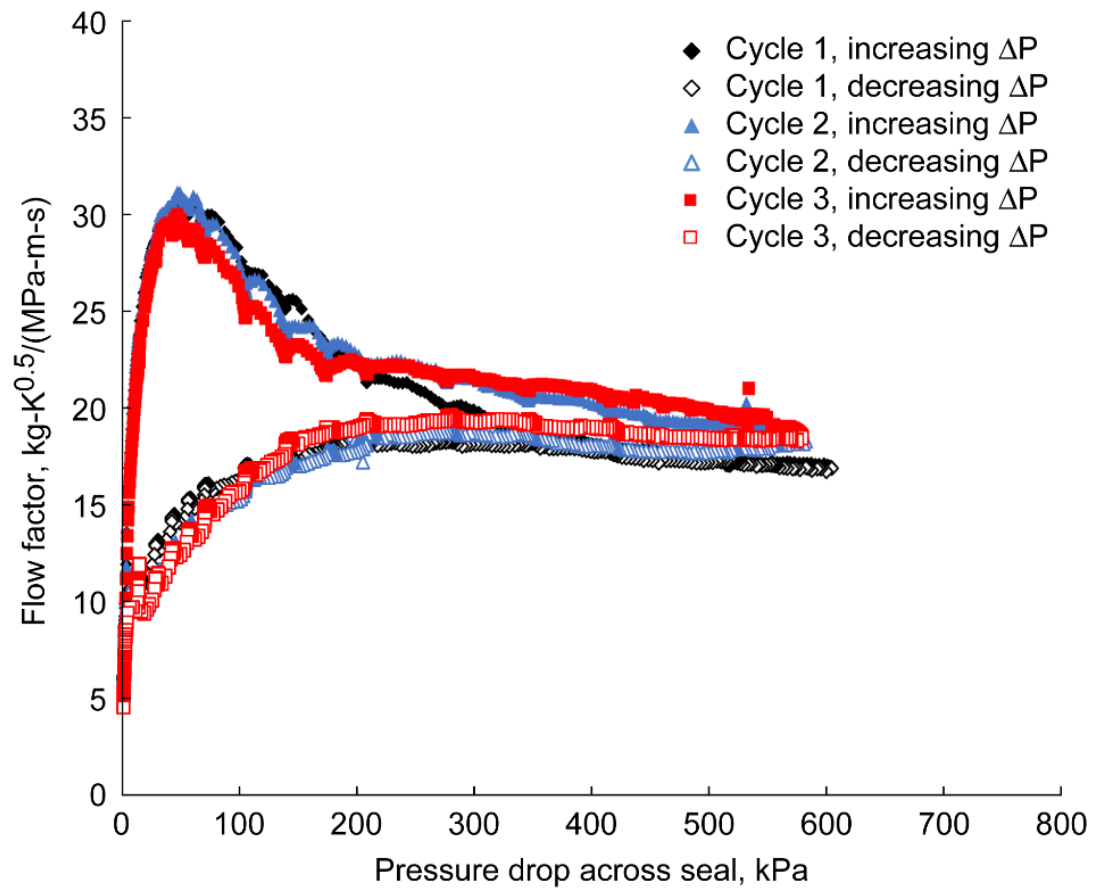

Figure 21. Static leakage performance of non-contacting finger seal with circumferential taper on lift pad, Build 6, at 859 to $921 \mathrm{~K}$ average inlet air temperature.

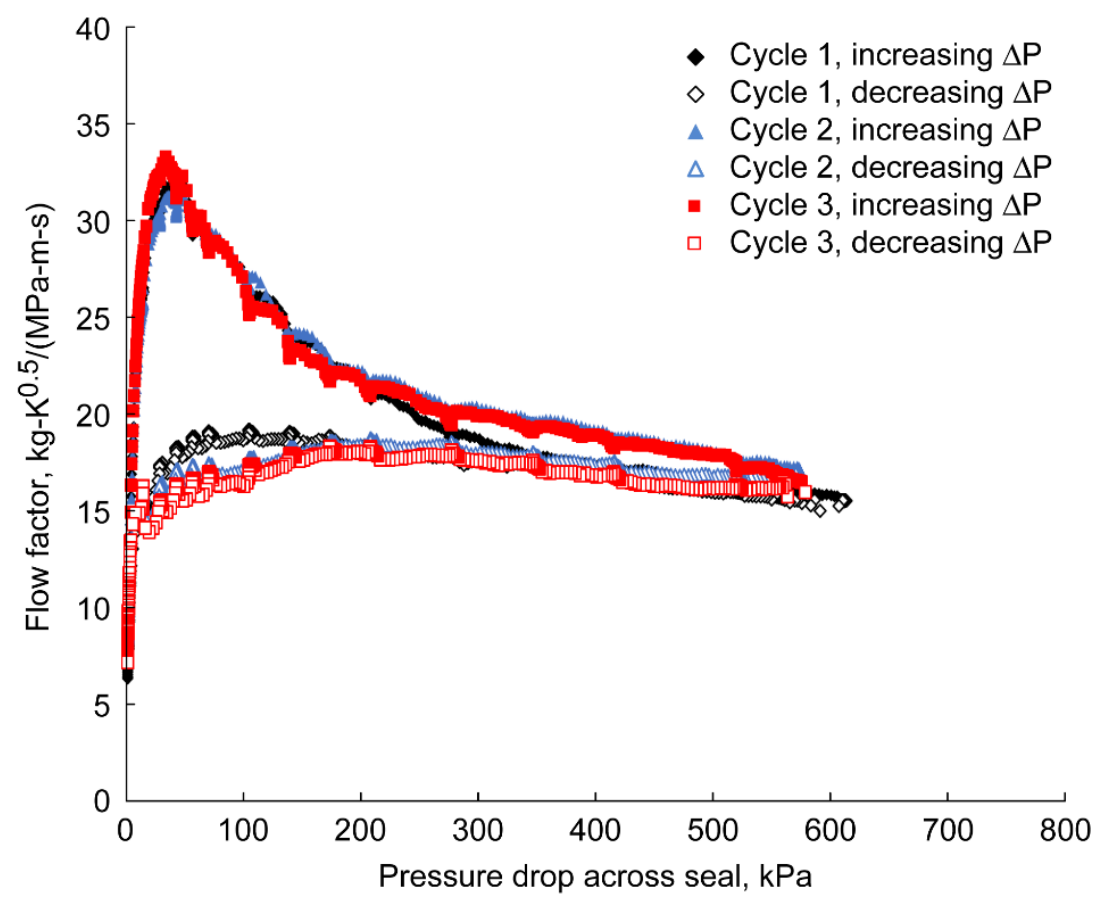

Figure 22. Static leakage performance of non-contacting finger seal with axial taper on lift pad, Build 7, at 866 to $908 \mathrm{~K}$ average inlet air temperature. 
Table 6. Bind-up test results: Pressure differential across the seal, kPa

\begin{tabular}{lcclc}
\hline $\begin{array}{c}\text { Build } \\
\text { no. }\end{array}$ & $\begin{array}{c}\text { Less free } \\
\text { wheeling }\end{array}$ & $\begin{array}{c}\text { Free wheeling } \\
\text { stopped }\end{array}$ & Tight & Comment \\
\hline 1 & 83 & 124 & 248 (faint squeak) & $2 \mathrm{~N}-\mathrm{m}$ at $248 \mathrm{kPa}$ \\
2 & 55 & 83 & $165-248$ & At 248 kPa light squeak \\
3 & 96.5 & 317 & 386 & At 517 kPa very hard to turn \\
4 & 96.5 & 303 & 344 & \\
4 at $672 \mathrm{~K}$ & 317 & 358 & 414 & At $150 \mathrm{kPa}, 6.8 \mathrm{~N}-\mathrm{m}$ \\
$5 \mathrm{a}$ & 68.9 & 262 & 372 & At $414 \mathrm{kPa}, 4 \mathrm{~N}-\mathrm{m}$ \\
$5 \mathrm{~b}$ & 83 & 138 & 345 & 414 \\
6 & 83 & 248 & 317 (faint squeak) & \\
7 & 96.5 & 276 & & \\
\hline \hline
\end{tabular}

\section{Bind-Up Pressure}

Results of the bind-up tests are summarized in Table 6, which shows the pressure differential at which the freewheeling decreased, stopped, and at which bind-up occurred. In a few cases, a faint metallic squeak could be heard indicating rubbing contact. Also, in some cases, a torque wrench was used to measure the bind-up torque.

Comparing the bind-up pressure differentials for Builds 1 and 2, it is observed that more pressure differential is needed to cause bind-up for Build 1 than Build 2. The Build 1 seal has a larger radial clearance between the forward finger and the rotor than Build 2 and it stands to reason that Build 1 would require more pressure differential to draw those fingers into the rotor than Build 2. A similar finding is evident in comparing Builds 3 and 4, which have the same aft finger element, but Build 3 has a larger radial clearance between the forward fingers and rotor than Build 4. Note in Table 6 that a bind-up test for Build 4 was conducted at $672 \mathrm{~K}\left(750^{\circ} \mathrm{F}\right)$, which found bind-up occurred at higher pressure differentials than at room temperature. This is due to the seal material having a higher coefficient of thermal expansion than the rotor, which increases the seal clearance.

Builds 1 and 3 have the same forward finger element, but Build 3 has an aft finger axial thickness approximately double that of the Build 1 seal. With the greater axial finger thickness, Build 3 would have greater stiffness and require more pressure differential to draw it into the rotor. The bind-up test results are consistent with this expectation with Build 3 binding up at $386 \mathrm{kPa}$ compared to Build 1 binding up at $248 \mathrm{kPa}$.

Comparing Builds 1 and 5a, which are the same seal, but on the herringbone-grooved rotor and smooth rotor, respectively, one can see that bind-up for Build 5a occurred at a much higher pressure differential than for Build 1. This is surprising, since the radial clearances for Build 5 a are smaller than for Build 1.

Comparing Build 3 to Build $5 \mathrm{~b}$, which is again the same seal but on the herringbone-grooved rotor and smooth rotor, respectively, the bind-up pressure for Build $5 b$ is lower than for Build 3. This is as expected since the Build $5 b$ seal has a smaller clearance than Build 3.

Comparing both Builds 6 and 7, which have 0.0127-mm (0.0005-in.) circumferential and axial tapers, respectively, on a smooth rotor, to Build 2, it can be seen that both Builds 6 and 7 bind-up at higher pressures than Build 2, even though they have smaller radial clearances than Build 2. This could be explained by the fact that the lift pads of Builds 6 and 7 do not have circumferential grooves. It is possible that without the circumferential groove, the pressure gradient under the lift pad is more gradual, resulting in a higher pressure under the lift pads to counteract the closing forces.

There is no intention to imply that the circumferential groove is bad. Rather, the circumferential groove is critical to the concept that uses the herringbone-grooved rotor. The circumferential groove, if designed properly, isolates the hydrodynamic lifting features from the hydrostatic effects and insures that there is low pressure on all four sides of the area on the lift pads where the herringbone-grooves pump. It may be possible to increase the bind-up pressure for this seal by increasing the radial clearance. The tapers on Builds 6 and 7 change the average clearance, making it a little bigger. The bind-up pressure depends on the pressure profile on the lift pads. For the lift pads with the tapers, it is possible that the hydrodynamic lift generated by shaft rotation may get overwhelmed by axial hydrostatic flows at high pressure differentials.

\section{E. Hardware Inspection}

Figure 23 shows a photograph of the herringbone grooved rotor outer diameter after the static performance test of the Build 1 non-contacting finger seal at $922 \mathrm{~K}$. This rotor was previously used for lift-off testing during which a continuous burnished track of no measurable depth was generated upstream of the herringbone grooves, presumably during startup and shutdown of rotation. Within this track there are periodic shiny rub spots. These resulted from the bind-up test in which a light squeak was heard. It shows that only a portion of each finger pad touched the rotor with 
enough force to cause damage. The location of the rub spots within the track suggests contact occurred at the leading edge of the aft fingers. Also, there is a heat pattern on the rotor outer diameter that likely corresponds to the flow.

Figure 24 shows a photograph of a sector of the inner diameter surface of the Build 1 non-contacting finger seal aft finger lift pads. A number of the lift pads have a shiny area on the upstream edge near the heel of the finger, which confirms the point of contact that caused the damage to the rotor in the bind-up test. The pattern in the discoloration is similar to that on the rotor outer diameter in Figure 23. The pattern resembles a spreading flow from a point source near the center of the upstream edge of each lift pad that fans out circumferentially as it moves axially downstream. Of course, that point source location corresponds to the gap between the forward fingers. It does appear that for some of the pads that there is a second triangular shape in the color that originates with a point nominally in the middle of the lift pad that fans out to the downstream edge of the lift pad. This second pattern is probably due to the land between the two rows of grooves on the rotor and the flow going through a smaller clearance at that point.

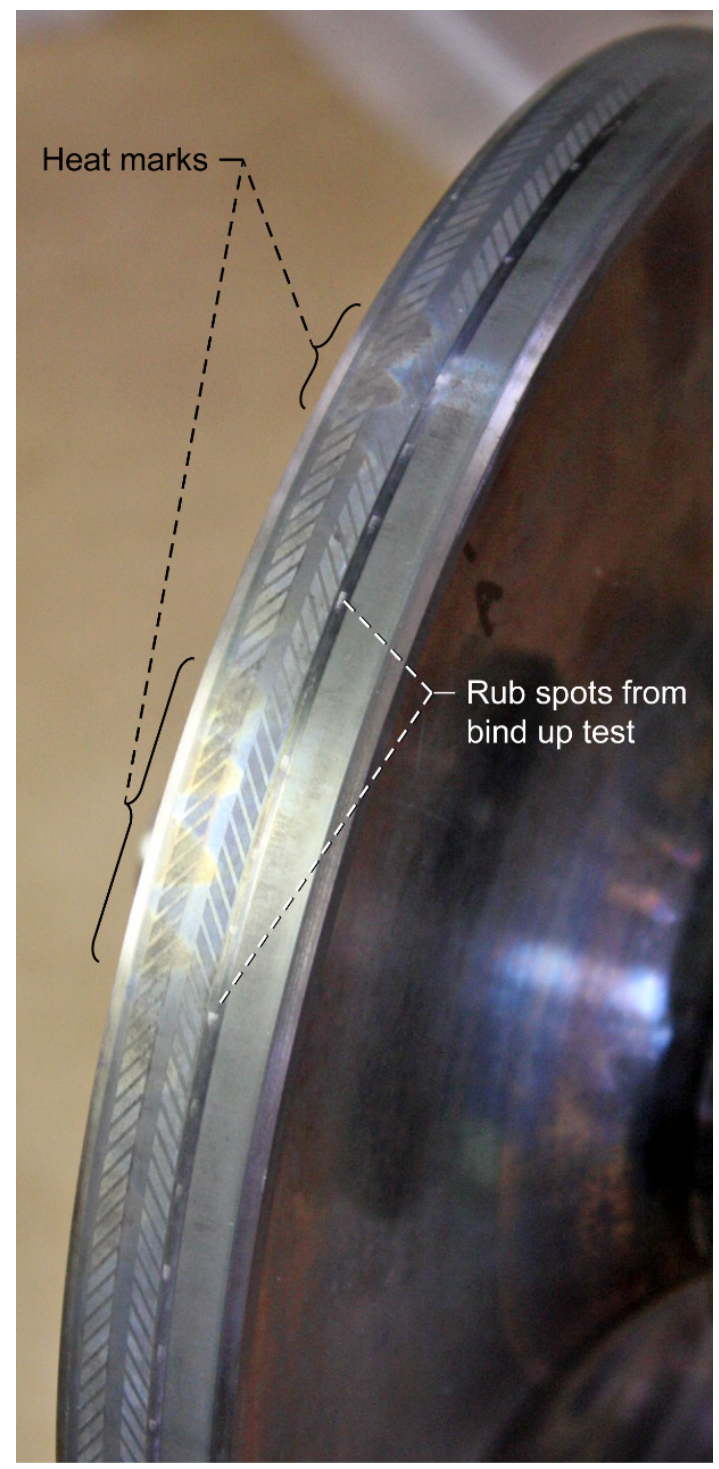

Figure 23. Herringbone-grooved rotor outer diameter after static performance test of Build 1 non-contacting finger seal at $922 \mathrm{~K}$ shows marks from bind-up test and heat discoloration indicative of air flows in the seal.

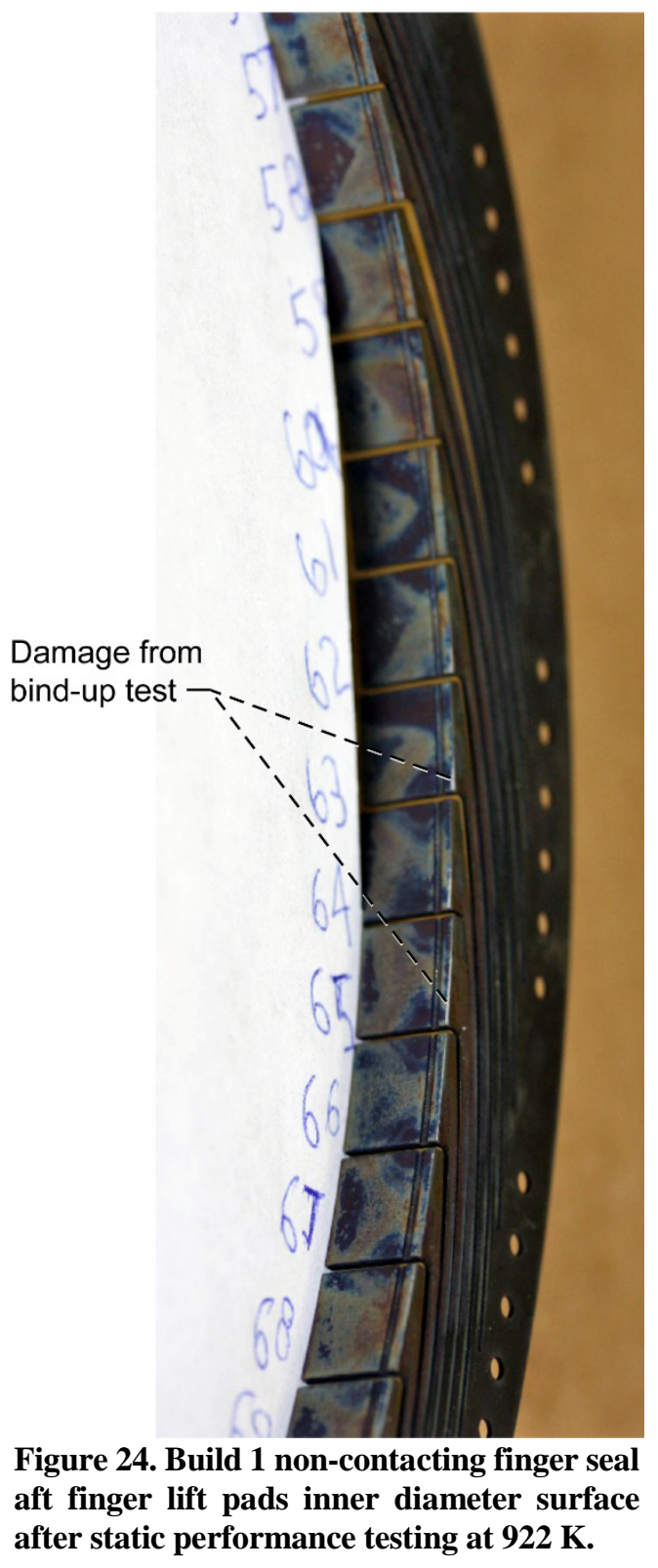




\section{Conclusions}

- The application of both pressure differential across the seal and some rotation is needed to optimally seat the seal for repeatable flow measurements.

- Bind-up of the non-contacting finger seal results from the pressure differential across the seal deflecting the fingers to contact the rotor. This contact occurs at the heel of the aft finger. Given the axial width of the wear mark caused by bind-up and the narrow burnish mark on the aft finger leading edge, it is possible that the aft finger deflects axially and twists slightly and/or some of the upstream finger contacts the rotor as well. The pressure differential at which bind-up occurs increases with increased radial clearance.

- Completely covering the gaps between the fingers by matching inner diameters of the forward and aft fingers significantly reduces the leakage.

- Longer seal lands as found in the tapered lift pads can cause more leakage with increasing pressure differential due to lifting of the fingers. The taper provides a path for more high pressure to get to the lift pad inner diameter and there is more area for the pressure to act compared to lift pads with a circumferential groove.

- The maximum pressure capability of the non-contacting finger seals tested at static conditions was between approximately 100 and $300 \mathrm{kPa}$ at $0 \mathrm{rpm}$. With centrifugal growth of the rotor affecting the seal clearance, the maximum pressure capability should be adjusted downward as speed is increased.

- The non-contacting finger seal with the axially thick finger and the same inner diameter of the forward and aft fingers (Build 4) had the lowest leakage at approximately $7 \mathrm{~kg}-\mathrm{K}^{0.5} /(\mathrm{MPa}-\mathrm{m}-\mathrm{s})$ and the least hysteresis.

- Performance testing below the maximum pressure capability is needed to determine if the hydrodynamic lifting forces will prevent contact as the shaft grows with shaft rotation.

\section{References}

1. Steinetz, B. M., Hendricks, R. C., and Munson, J., “Advanced Seal Technology Role in Meeting Next Generation Turbine Engine Goals,” NASA TM-1998-206961, April 1998.

2. Arora, G. K., Proctor, M. P., Steinetz, B. M., and Delgado, I. R., "Pressure Balanced, Low Hysteresis, Finger Seal Test Results,” NASA TM-1999-209191, June 1999; also AIAA Paper 99-2686, June 1999.

3. Arora, G. K., and Proctor, M. P., “JTAGG II Brush Seal Test Results,” NASA TM 107448, July 1997; also AIAA paper 972632, July 1997.

4. Arora, G. K., U.S. Patent for “Non-Contacting Finger Seal With Hydrodynamic Foot Portion,” Patent No. 5,755,445, May 26, 1998.

5. Proctor, M. P. and Steinetz, B. M., U.S. Patent for “Non-Contacting Finger Seal,” Patent No. U.S. 6,811,154 B2, Nov. 2, 2004.

6. Braun, M. J., Deng, D. F., Pierson, H. M., Proctor, M. P., and Steinetz, B. M., “A Three Dimensional Thermofluid Analysis and Simulation of Flow, Temperature, and Pressure Patterns in a Passive-Adaptive Compliant Finger Seal," The 10th International Symposium on Transport Phenomena and Dynamics of Rotating Machinery, Honolulu, Hawaii, March 7-11, 2004, ISROMAC102004-126.

7. Braun, M. J., Pierson, H. M., Deng, D. F., Choy, F. K., Proctor, M. P., and Steinetz, B. M., "Structural and Dynamic Considerations Towards the Design of a Padded Finger Seal,” 39th AIAA/ASME/SAE/ASEE Joint Propulsion Conference, Huntsville, Alabama, July 20-23, 2003, AIAA-2003-4698.

8. Marie, H., “A Study of Non-Contacting Passive-Adaptive Turbine Finger Seal Performance, Volume 1,” Ph.D Dissertation, University of Akron, Akron, OH, 2005.

9. Braun, M. J., Marie, H., and Smith, I., U.S. Patent for “Double padded finger seal," Patent No. U.S. 7,735,833, June 15, 2010.

10. Proctor, M. P. and Delgado, I. R., "Preliminary Test Results of a Non-Contacting Finger Seal on a Herringbone-Grooved Rotor,” NASA TM 2008-215475, November 2008; also AIAA Paper 2008-4506, July 2008. 